\title{
Development of a Generic Tool to Design Scroll Expanders for ORC Applications
}

\author{
Pardeep Garg ${ }^{1}$, Karthik G.M. ${ }^{1}$, Prashant Kumar ${ }^{2}$ and Pramod Kumar ${ }^{1 *}$ \\ ${ }^{1}$ Department of Mechanical Engineering \\ ${ }^{2}$ Centre for Atmospheric and Oceanic Sciences \\ Indian Institute of Science \\ Bangalore 560012 India
}

\begin{abstract}
Successful experimental studies on the scrolls that are reverse engineered to operate in the expansion mode recommend their use in the ORCs over conventional turbines when the power capacities lie in the range of $1-50 \mathrm{kWe}$. However, when it comes to the design of a new scroll expander for a particular ORC requirement, an ORC engineer hardly finds any guidelines in terms of selecting the geometric features of scroll such as height, involute base circle radius, number of expansion chambers, etc. This paper is motivated by such a philosophy wherein we develop a generic framework, capable of obtaining efficient scroll geometries for any ORC specifications including the working fluid. The process of finding the most efficient geometry involves the estimation of losses inherent to scroll such as leakages, supply pressure drop, under/over expansion and other mechanical losses. This framework is validated using the experimental data available in literature and a detailed case study of designing scroll expanders for R134a is presented to highlight the effect of operating conditions and geometric features on the loss mechanisms. It is found that there exists a unique scroll height (or aspect ratio) that results in the maximum isentropic efficiency for the given set of operating conditions. Further, this work is extended to the design of scroll expanders for various working fluids in the ORC regime. In this regard, it is found that high condenser pressure fluids such as R134a, R152a and isobutane are more suited in scroll expanders as their cycle volume ratio matches with the optimum scroll volume ratio (2-5).
\end{abstract}


27 Keywords: Organic Rankine cycles, volumetric expander, scroll expander, design guidelines,

28 scroll geometry, isentropic efficiency, losses in scroll expander

$29 *$ Corresponding author. Fax: +91 8023604536 email: pramod@ mecheng.iisc.ernet.in

\section{$30 \quad$ Nomenclature}

$31 \quad A_{s u}$

$32 b$

$33 b_{\text {opt }}$

$34 \quad F_{i}$

$35 \quad F_{r}$

$36 \quad F_{t}$

$37 f_{x 1,} f_{x 2}, f_{y 1}, f_{y 2}$

$38 \quad h$

$39 \quad I_{o}$

$40 \quad L_{Q}$

$41 \quad L_{S}$

$42 \dot{m}$

$43 \quad M_{o}$

$44 \quad m_{s}$

$45 \quad N$

$46 p$

$47 \quad r_{b}$

$48 \quad r_{o}$

$49 \quad R_{p}$

$50 \quad R_{v}$

$51 \quad T$ suction area

$\mathrm{m}^{2}$

scroll height

optimum scroll height

axial force

radial force

tangential force

frictional force at Oldham ring $\mathrm{N}$

enthalpy

$\mathrm{kJ} / \mathrm{kg}$

crank shaft moment of inertia $\mathrm{kgm}^{2}$

frictional torque at crank journal $\mathrm{Nm}$

frictional torque at crank pin $\quad \mathrm{Nm}$

mass flow rate

$\mathrm{kg} / \mathrm{s}$

gas moment

$\mathrm{Nm}$

mass of orbiting scroll

generator load

pressure

base circle radius

orbiting radius

pressure ratio

expansion ratio

temperature $\mathrm{m}$

$\mathrm{m}$

$\mathrm{N}$

$\mathrm{N}$

$\mathrm{N}$ 
52

$53 \theta$

$54 \omega$

$55 \rho$

$56 \quad 1$ to 6

57

58 Superscript

59

60

61 volume

scroll orbiting angle

angular speed

density

states in ORC

states on real thermodynamic cycle $\mathrm{m}^{3}$

rad

$\mathrm{rad} / \mathrm{s}$

$\mathrm{kg} / \mathrm{m}^{3}$ 


\section{Introduction}

Unmatched and surging demand of energy motivates the engineering community to

efficiently realize even the marginal potential of low temperature heat $\left(\sim 150{ }^{\circ} \mathrm{C}\right)$ that is available in plenty in form of renewable resources such as geothermal and solar. Further, these sources are distributed spatially ranging from $\mathrm{kW}$ to $\mathrm{MW}$ of thermal making the scalability a key feature of the technology to be chosen to convert this heat into electricity. organic Rankine cycle (ORC) is one of the possible technologies which is scalable in the above range and can efficiently generate electricity [1-4]. While designing such an ORC, selection procedures for components like pump and heat exchanger are established except for the expander, in particular, at power scales below $50 \mathrm{kWe}$ [5]. In these situations, the most common type of expander which is the turbine type tends to have high rotational speeds $\left(>10^{4} \mathrm{rpm}\right)$ and suffers from low isentropic efficiency [6]. Positive displacement device such as the scroll expander has been proposed as a potential candidate for sub-MWe ORC applications $[7,8]$.

Literature reports on scroll reveal that scroll has traditionally been used as a compressor in the air conditioning industry [9-13] and since the last two decades, it has gained interest as an expander [7,8,14-25] for power generation in micro-scale ORCs. Modifying a scroll compressor (designed for air conditioning) and operating it in the reverse direction has been a typical experimental methodology to obtain scroll expander characteristics. Such a practice can be dated back to 1994 when Zanelli et al. used a modified scroll compressor to measure its isentropic efficiency in the expander mode [7]. They have reported an isentropic efficiency of $63-65 \%$ for R134a at a source temperature of $80{ }^{\circ} \mathrm{C}$. Since then, a number of research groups have carried out similar studies for different working fluids (steam [14], R113 [15], R134a [16], R123 [17], R245fa [18-20]) and different power capacities in the range of $1-15 \mathrm{kWe}$. These experimental results have guided a significant 
amount of work towards developing analytical [18-24] and simulation models [25,26] to predict the expander performance using deterministic models. For example, Lemort et al. carried out experimental studies with R-245fa and used the performance data to develop a semi-empirical model $[18,19]$. Similarly, Orosz et al. analyzed non-uniform wall thickness scrolls to accommodate higher volume ratios with a fewer number of wraps [21-23]. However, even with such extensive work on scroll expander, there exist little guidelines for the ORC engineers to design and develop the scroll expander specific to their ORC requirements.

Present work addresses this necessity by developing a scroll design model which is generic in nature and capable of generating efficient scroll geometries for the ORC specifications in the range of 1 to $50 \mathrm{kWe}$. Search for the efficient geometry is conducted in the domain containing the various feasible scroll heights. Efficiency of these scroll geometries is estimated by accounting the inherent losses such as flank and radial leakage, supply pressure drop and under- / over- expansion. Scroll model developed in this paper also estimates the mechanical losses which are either neglected [27] or assumed to be independent of the geometric features [18]. In this regard, work of Ishii et al. [28-31] on estimating the mechanical losses in scroll compressors is adopted. The model is validated using the work in [20] and its features are presented in detail by performing a case study on ORC with R134a working fluid. This model is further extended to analyze the effect of working fluid on the design of an efficient scroll expander.

\section{Scroll expander in an ORC}

It can be comprehended from the literature that scroll expander is seen as a natural choice for the expander in ORCs with the power capacity lying in the range 1-50 kWe. Its construction (Fig. 1) is intricate in the sense that at any given instant spiral walls of the 
moving and the fixed scroll form a number of chambers with each trapping the gas at different temperature and pressure. As the gas expands in these chambers, moving scroll translates in a circular orbit. Number of these chambers formed during expansion process, in general, is a key variable that determines the built-in volume ratio of scroll expander. Ideally, this volume ratio should match with the volume expansion ratio of working fluid in the power cycle to avoid under or over expansion; a typical loss mechanism exhibited by any positive displacement device. This highlights the need of understanding the constraints imposed from the power cycle while designing a scroll expander. Thus, the foremost step in the design of a scroll expander is to define the operating conditions of the ORC along with the mass flow rate and volume ratio.

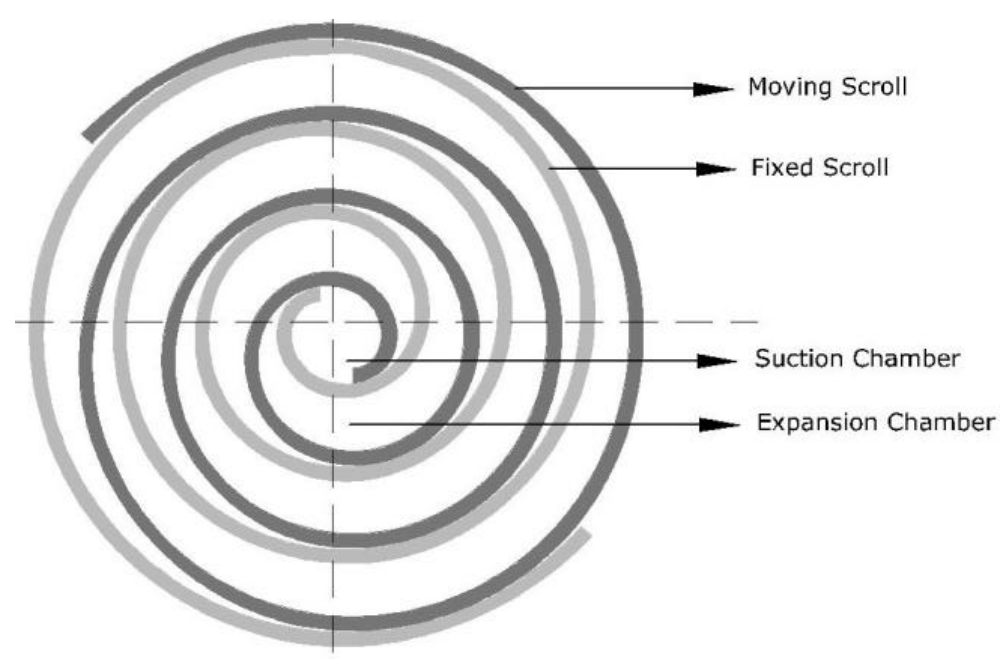

Fig. 1. Typical schematic of a scroll expander

Fig. 2 gives an overview of the methodology of designing the scroll expander for

ORC applications. Once the operating conditions across the scroll are identified using the 

models. These models are discussed in detail in next section.
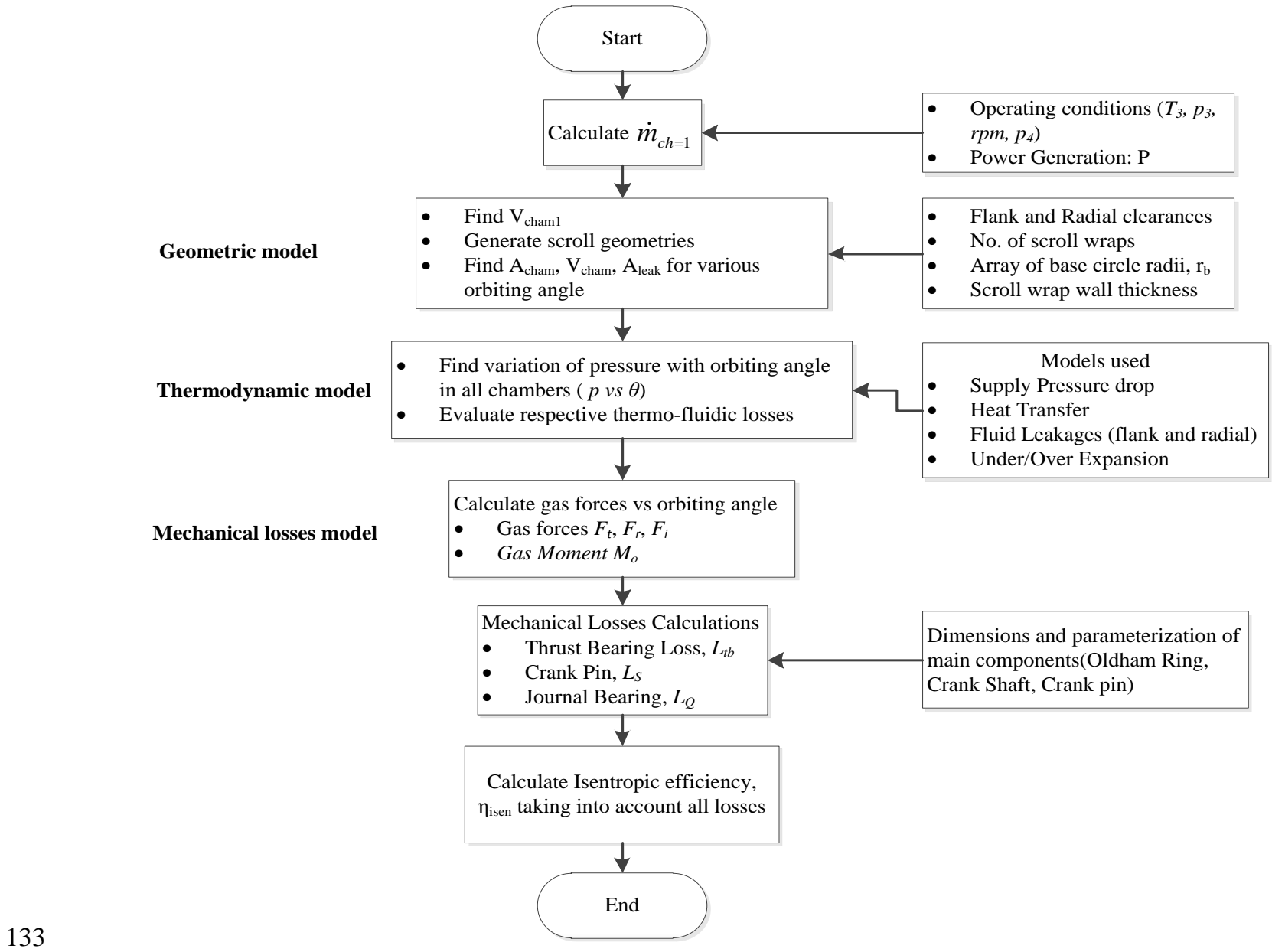

- $\quad$ Operating conditions $\left(T_{3}, p_{3}\right.$,

$\left.r p m, p_{4}\right)$

Power Generation: P

Fig. 2. Algorithm to design scroll expanders

\section{Scroll modeling}

\subsection{ORC model}

Fig. 3 shows the schematic of the thermodynamic cycle with its major components viz. pump, regenerator, boiler, scroll expander and condenser. Modeling details for such a 
140 cycle can be found in [32-34] and are not repeated here. However, for the sake of 141 completeness, key assumptions are briefed below.

142 i. While the minimum temperature in the cycle $\left(T_{l}\right)$ is set at $45^{\circ} \mathrm{C}$, the maximum temperature $143\left(T_{3},\right)$ is varied to study its impact on scroll design.

144 ii. Pump efficiency is $90 \%$.

$$
\eta_{\text {pump }}=\frac{h_{2}-h_{1}}{h_{2^{\prime}}-h_{1}}
$$

iii. Pressure drop during heat transfer on the high and the low side pressure are $3.5 \%$ of the pump outlet and expander exhaust pressure respectively. Mathematically,

$$
\begin{gathered}
p_{3^{\prime}}=0.965 p_{2^{\prime}} \\
p_{1^{\prime}}=0.965 p_{4^{\prime}}
\end{gathered}
$$

iv. Majority of results in the paper are presented for the power of $10 \mathrm{~kW}_{\mathrm{e}}$ which is defined as

$$
\dot{P}=\dot{m}_{w f}\left(\left(h_{3^{\prime}}-h_{4^{\prime}}\right)-\left(h_{2^{\prime}}-h_{1}\right)\right)
$$

v. Both the heat exchangers; namely, regenerator and boiler are modeled for a pinch temperature of $10^{\circ} \mathrm{C}$.

vi. As a starting point, scroll expander efficiency is assumed to be unity and later calculated using scroll analysis model.

Objective function for selecting the operating conditions (inlet/outlet pressure, mass flow rate, etc.) across scroll expander at the given scroll inlet temperature is the maximization of cycle efficiency. Mathematically,

$$
V R_{o p t}=\left.V R\right|_{\frac{\partial \eta}{\partial V R}=0}
$$

However, efficiency variation, in some cases, tends to become asymptotic beyond a certain expansion ratio resulting in a significantly high volume ratio without any substantial 

to

$$
V R_{o p t}=\left.V R\right|_{\frac{\partial \eta}{\partial V R}=0.01}
$$

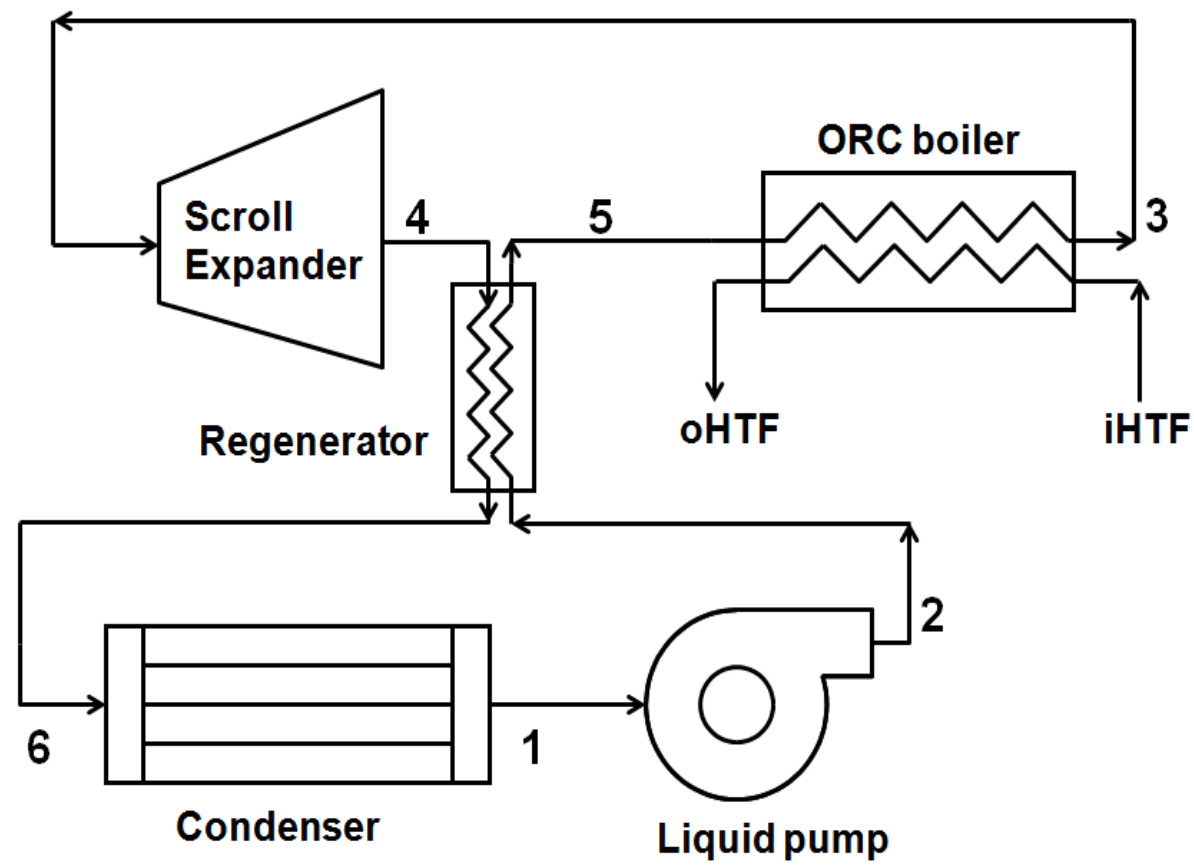

Fig. 3. Schematic of an ORC

\subsection{Geometric Model} model such as volume ratio, scroll inlet pressure, temperature and mass flow rate, geometries with various combinations of involute circle radius and height are generated for the identical volumetric displacement. Maximum dimension in the radial direction, also termed as scroll diameter in this paper is measured as the Euclidian distance between the extreme points on the fixed scroll and is used to define the aspect ratio (Fig. 1). Mathematically,

$$
A R=\frac{d}{b}
$$



area, chamber volume and leakage area corresponding to flank and radial leakage with the orbiting angle are also determined in this model.

\subsection{Thermodynamic model}

This model takes the input from the ORC and Geometric Model and estimates the individual chamber pressure variation with the orbiting angle. Methodology followed is to solve the continuity and the unsteady energy equation for each chamber against the scroll motion. While these chambers are considered to be nodes in the space and scroll motion is discretized over the complete cycle of $2 \pi$ (one cycle of scroll motion) using a FTFS (forward in time and forward in space) scheme. This enables the model to characterize the variation of pressure, temperature and the amount of leakages in each chamber with the orbiting angle. Knowledge of pressure variation during the scroll motion leads to the assessment of area occupied by the expansion process on the P-V diagram and hence, the work produced. Mathematically, it is given as

$$
W_{\text {actual }}=\sum_{c h=1}^{c h=n} \int_{\left.V\right|_{\theta=0}}^{\left.V\right|_{\theta_{0}=2 \pi}} p d V
$$

Irreversibilities during the expansion process make the pressure profile on $\mathrm{P}-\mathrm{V}$ diagram deviate from the isentropic one and cause loss of efficiency. The magnitude of inefficiency depends upon a number of factors including the geometric features and the nature of loss mechanisms. These loss mechanisms are estimated individually for these chambers as the scroll translates from 0 to $2 \pi$. Following losses are considered to calculate the inefficiencies. 


\subsubsection{Supply pressure drop}

Ideally, the suction process in a scroll expander is isobaric. This, however, is not realized in practice due to irreversibilities generated in form of pressure drop driving the suction process in finite time. Pressure drop associated with this process is calculated using the principles of fluid mechanics governing the fluid flow in a converging nozzle. Since the volume of the suction chamber increases at a non-linear rate with the orbiting angle, mass flow rate during suction can also be expected to have a similar dependence on the orbiting angle. To arrive at the final mass flow rate, initially, a nominal mass flow rate is calculated and finally is updated to account for the leakages occurring from the chamber 1 to 2.

$$
\begin{gathered}
\dot{m}_{c h=1}(\theta)=A_{\text {inlet }}(\theta) \rho_{3^{\prime}} \sqrt{2\left(h_{3^{\prime}}-h_{c h=1}(\theta)\right)} \\
\dot{m}_{c h=1}(\theta)=\dot{m}_{c h=1, \text { nominal }}(\theta)+\dot{m}_{\text {leakage from ch }=1 \rightarrow 2}(\theta)
\end{gathered}
$$

\subsubsection{Flank Leakage}

Fluid leakage from high pressure to low pressure chamber along the flank walls of the scroll is termed as flank leakage (Fig. 4 (a)). Leakage amount is calculated using a similar nozzle equation (Eq. 10) but with the flank leakage area characterized by the scroll height and the flank clearance between the fixed and the moving scroll. Mathematically,

$$
\dot{m}_{\text {leakage, flk, ch=j } \rightarrow \mathrm{j}+1}(\theta)=A_{\text {leakage, flk, } \mathrm{j}-\mathrm{j}+1}(\theta) \rho_{j}(\theta) \sqrt{2\left(h_{j}(\theta)-h_{j+1}(\theta)\right)}
$$

\subsubsection{Radial Leakage}

Fluid leaking out of the clearances between the moving and the fixed scroll at their top and bottom plane along the spiral length is termed as radial leakage (Fig. 4 (b)). Since the leakage flow is defined over a finite length (scroll thickness in this case), equations governing the nozzle flow used in the calculation of flank leakage cease to be applicable. In such a 
scenario, flow due to radial leakage can be represented by Poiseuille's flow with radial clearance as the hydraulic diameter and thickness as the length of equivalent pipe. Mathematically,

$$
\dot{m}_{\text {leakage, rad, ch }=\mathrm{j} \rightarrow \mathrm{j}+1}(\theta)=A_{\text {leakage, rad, } \mathrm{j}-\mathrm{j}+1}(\theta) \sqrt{\frac{2 C_{\text {radial }} \rho_{j}(\theta) \Delta p_{\mathrm{j} \rightarrow \mathrm{j}+1}(\theta)}{t_{\text {scroll }} f}}
$$

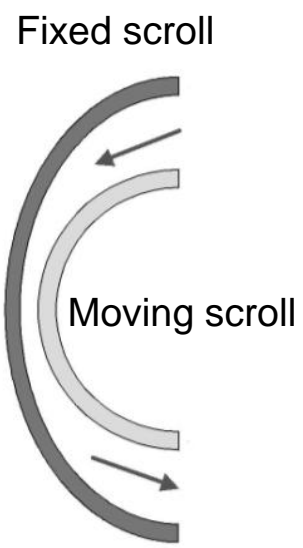

Flank leakage

\section{Fixed scroll}

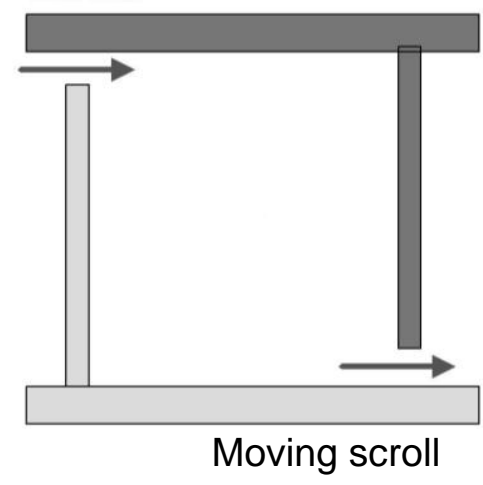

Radial leakage

Fig. 4. Schematic for the radial and flank leakage

\subsubsection{Under or over-expansion}

Exhaust gas from the scroll expander in the ORC is subjected to the condenser pressure and there can be a situation when the pressure of the exhaust gas $\left(p_{e x}\right)$ is different from the condenser pressure. This translates into two cases, a) $p_{e x}>p_{4}$, or b) $p_{e x}<p_{4}$, termed as under or over expansion, respectively, as shown in Fig. 5. In such a situation, the exhaust gas (available at the end of expansion in closed chambers) undergoes an isochoric expansion or compression. The loss in isentropic work is represented by the hatched region (triangle type structure) on the P-V chart as shown in Figs. 5 (c) and 5 (d) for under and overexpansion, respectively. The lost work is estimated by extrapolating the pressure profile to the condenser pressure and then calculating the area of the triangle type structure. The fact 
that the slope of pressure profile on P-V chart decreases in magnitude with displacement, the lost work in an over expansion condition is bound to be greater than the one in under expansion for the identical pressure difference situation.

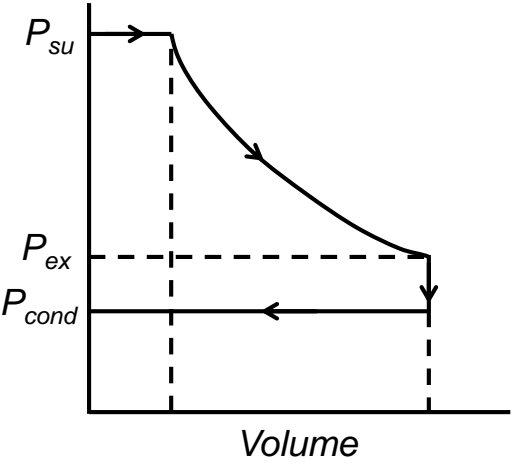

a)

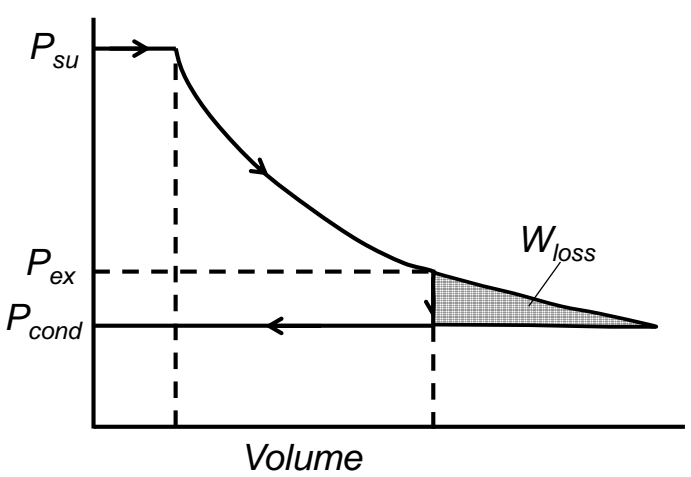

c)

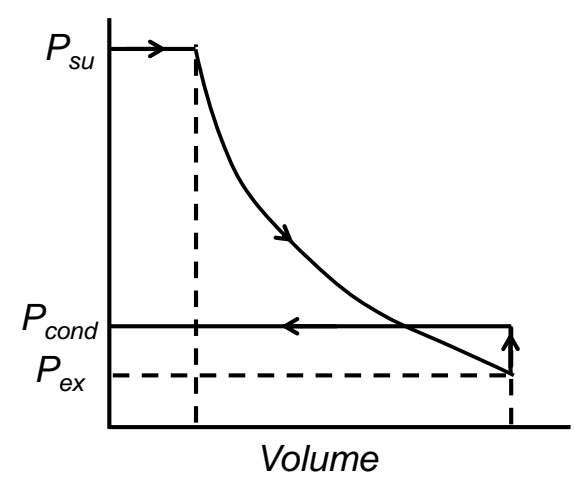

b)

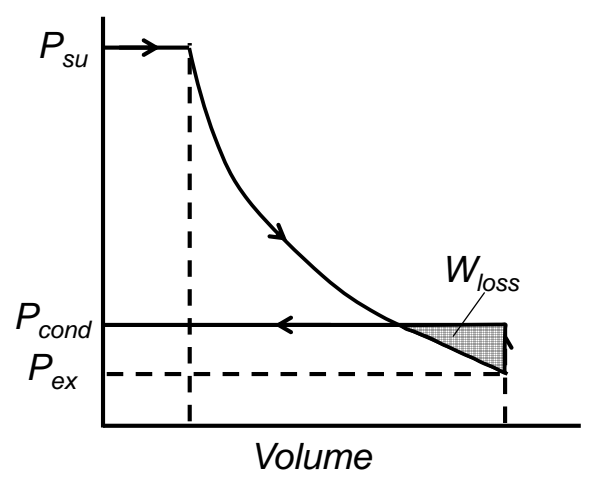

d)

Fig. 5. Schematic for under/over expansion loss. While Figs. a) and c) represent the case for under-expansion, Figs. b) and d) depict the over-expansion case.

\subsection{Mechanical Model}

Ishii et al. [29] in 1986 built a comprehensive model to predict mechanical losses in a scroll compressor. In this paper, their model is modified for a scroll expander and integrated to the previously discussed models. Figs. A1 to A3 in appendix A are redrawn from [29] which present the details of various forces and moments acting on the different parts of scroll 
expander. Calculation of these moments involves the resolving of the gas forces exerted on the scroll wall in the radial and tangential direction. Its modeling details can be found in our previous work [35]. Portion of the moment available from the gas is lost in overcoming frictional and over turning moment. Net moment transferrable $(N)$ to the generator is obtained by solving the equation given below.

$$
\begin{aligned}
& \left(I_{o}+m_{s} r_{o}^{2}+m_{o} r_{o}^{2} \sin ^{2} \theta\right) \ddot{\theta}-\left(m_{o} r_{o}^{2} \sin \theta \cos \theta\right) \dot{\theta}^{2}=-N+F_{t} r_{o}- \\
& \left\{L_{Q}+L_{S}+\left(f_{x 1}+f_{x 2}\right) r_{o} \cos \theta+\left(f_{y 1}+f_{y 2}\right) r_{o} \sin \theta+\left(f_{t 1}+f_{t 2}\right) r_{o}\right\}
\end{aligned}
$$

Integrating the above equation over an entire rotation of $2 \pi$, the following equation is obtained where each term represents the average work produced in one rotation

$$
N \omega=F_{t} r_{o} \omega-\left\{L_{s}+L_{q}+\left(f_{t 1}+f_{t 2}\right) r_{o}+\frac{1}{2 \pi} \int_{0}^{2 \pi}\left(f_{x 1}+f_{x 2}\right) r_{o} \cos \theta d \theta+\frac{1}{2 \pi} \int_{0}^{2 \pi}\left(f_{y 1}+f_{y 2}\right) r_{o} \sin \theta d \theta\right\} \omega
$$
(A) (B)
(C)
(D)

where the term A is the net-work output available on the power shaft, B is the work produced due to the gas force, $\mathrm{C}$ is the loss due to friction in the crank pin and journal bearing, $\mathrm{D}$ is the frictional loss in the thrust bearing and $\mathrm{E}$ denotes the frictional loss due to the Oldham coupling. These losses are discusses in the subsequent section.

\subsubsection{Frictional loss at crank pin and Journal bearing $(\mathrm{C})$}

Crank pin is fixed on the offset crank and rotates within the orbiting scroll sleeve bearing, providing the necessary degree of freedom to convert orbiting motion of the scroll to shaft rotation. $L_{S}$ represents the frictional torque loss at the crank pin. The crankshaft which transfers power from the scroll to the generator passes through a journal bearing. The frictional loss at this bearing is also calculated using Coulomb's law of friction and is represented by $L_{Q}$. 


\subsubsection{Thrust Bearing Losses (D)} constraint forces preventing the overturning of the orbiting scroll are supported by the thrust represent the thrust bearing losses.

\subsubsection{Frictional loss at Oldham coupling (E)}

The Oldham coupling slides between the moving scroll and the guide slot on the casing of the scroll machine. The frictional loss due to sliding is very small as compared to other losses.

All calculations were carried out on MATLAB (R-2011b) platform, which was programmed to invoke REFPROP 9.0 database for all thermodynamic property calculations.

\subsection{Scroll related assumptions}

i. The number of scroll turns (wraps) is fixed such that scroll exhaust pressure equals the condenser pressure when all the potential losses in the Thermodynamic Model are absent (switched off).

ii. The scroll wrap wall thickness is $4 \mathrm{~mm}$ which ensures sufficient strength of the scroll wrap walls as analyzed by Remi Dickes [24]. This is kept constant throughout the paper.

iii. RPM is fixed to 3000 ensuring that the gear box and the associated losses with it are avoided. However, this is not a strict criterion to choose RPM of the scroll expander. 


\section{Results and discussions}

The model developed in this paper is first validated with experimental results of Declaye et al. [20] in which they use R245fa as a working fluid in a scroll expander having a built-in volume ratio of 2.75 and operating at inlet conditions of $\sim 105{ }^{\circ} \mathrm{C}$ and 12 bar. In the absence of geometric features of scroll expander used in their set-up, it was assumed that their scroll had an aspect ratio of 5 which corresponds to the scroll height of $\sim 3 \mathrm{~cm}$ in our model. Since their studies involve a single scroll expander and its characterization against under/over expansion, performance of the above mentioned scroll is evaluated under the similar circumstances. The present model is found to be in good agreement with the experimental data as shown in Fig. 6 wherein the power predicted by our model is plotted against the pressure ratio (for under and over expansion) for the radial and flank clearances of 29 and $46 \mu \mathrm{m}$, respectively. Further, these clearances are set in the rest of paper to design the scroll expanders for various scenarios.

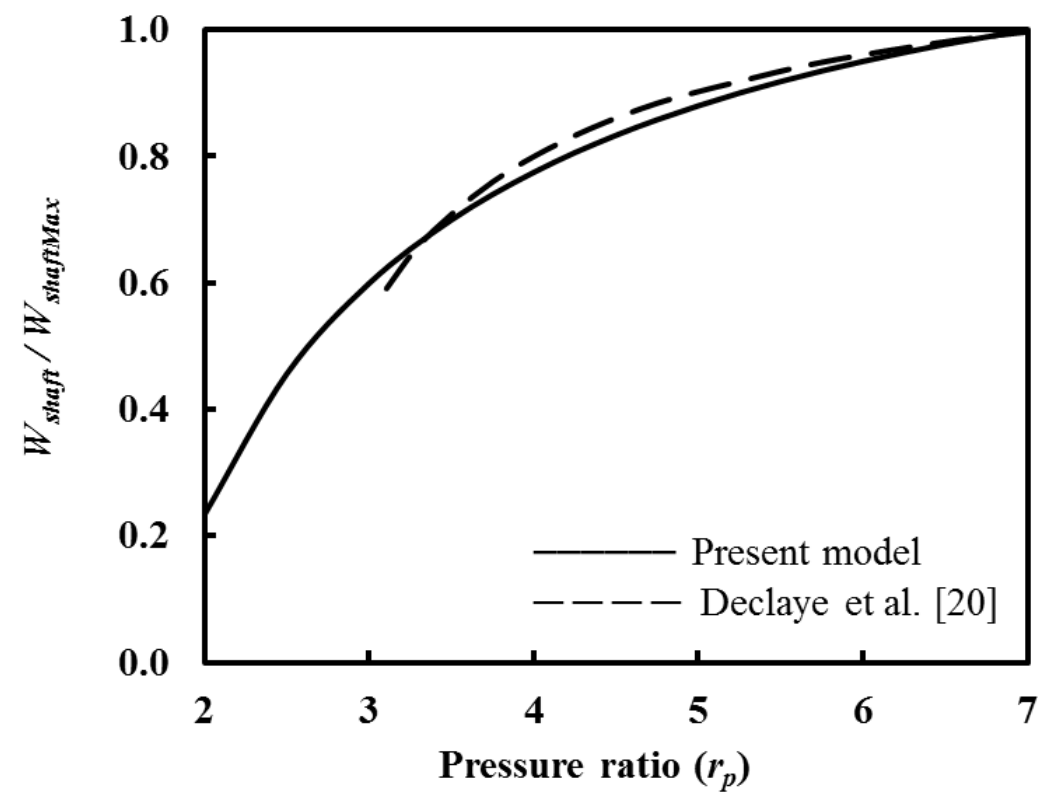

Fig. 6. Validation of scroll model with [20].

\subsection{Scroll analysis for R134a as a case study}


In order to understand the relative importance of loss mechanisms considered in this

paper against the geometric features and the operating conditions across a scroll expander, a case study with R134a as a working fluid in the ORC is performed. The net power generation considered is $10 \mathrm{kWe}$ for the various expander inlet temperatures ranging from 100 to $150{ }^{\circ} \mathrm{C}$ in the steps of $10{ }^{\circ} \mathrm{C}$. Corresponding expander-inlet pressures are chosen at which the cycle efficiencies are optimized based on the criterion discussed in the previous section and are reported in Table 1. Scroll exhaust pressure $\left(p_{4}\right)$ is fixed to 12.01 bar corresponding to the saturation pressure of $\mathrm{R} 134 \mathrm{a}$ at $45{ }^{\circ} \mathrm{C}$. Various other data like volumetric and pressure expansion ratio across the scroll are also tabulated in Table 1.

Table 1. Optimum performance data at the various scroll inlet temperatures in case of R134a

\begin{tabular}{ccccc}
\hline & Optimum & Optimum & Optimum & Optimum \\
$T_{3}\left({ }^{\circ} \mathrm{C}\right)$ & $R_{p}$ & $\eta_{\text {cycle }}(\%)$ & $R_{v}$ & $p_{3}(\mathrm{bar})$ \\
\hline 100 & 2.80 & 10.17 & 3.17 & 33.61 \\
110 & 2.97 & 11.11 & 3.30 & 35.76 \\
120 & 3.31 & 12.31 & 3.66 & 39.74 \\
130 & 3.63 & 13.50 & 3.99 & 43.61 \\
140 & 4.01 & 14.68 & 4.38 & 48.15 \\
150 & 4.40 & 15.85 & 4.78 & 52.90 \\
\hline
\end{tabular}

Firstly, a database of feasible scroll geometries is generated to search for the one with minimum overall losses for various scroll inlet temperature as shown in Fig. 7. For a given scroll inlet isotherm which also corresponds to an iso-volume curve, an inverse relationship is found to exist between the involute base circle radius $\left(r_{b}\right)$ and the height $(b)$ of the scroll. 
Mathematical relationship between the scroll height and involute base circle radius can be represented as

$$
R_{b} \propto \frac{1}{b^{n}}
$$

where $n$ is found to lie between 0.3 to 0.4 for the scrolls inlet isotherms analyzed above.

When the scroll height is kept constant but scroll inlet temperature $\left(T_{3}{ }^{\prime}\right)$ is increased, the involute base circle radius to generate the identical power decreases. This is attributed to the reduced volume of the suction cavity which, in turn, is associated with the declined mass flow rate (due to increased cycle efficiency) and the increased density of the suction gas. Each of these isotherms represents 50 distinct scroll geometries. Modeling a single geometry with the losses inherent to it takes about 20 minutes on a typical computational machine of the configuration mentioned in Table 2. Thus, modeling one working fluid for 6 distinct temperatures takes $\sim 4$ days of computational time.

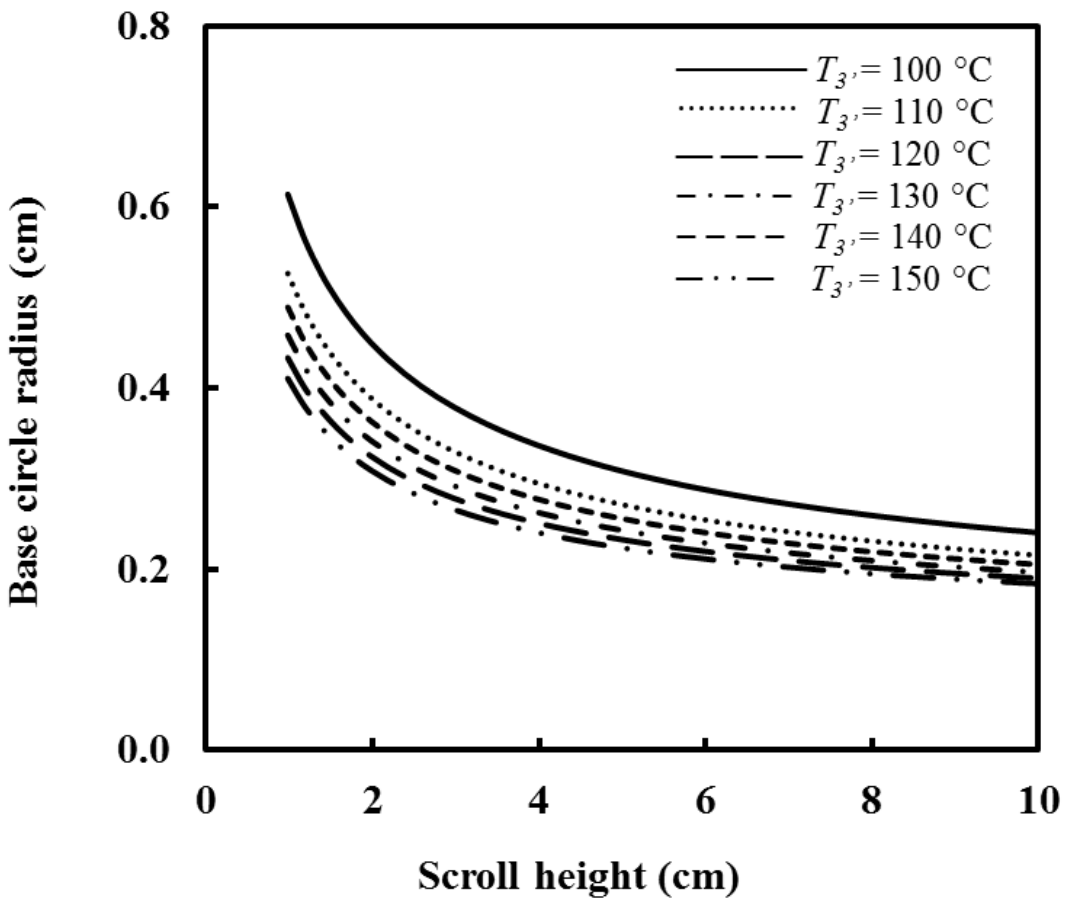

Fig. 7. Variation of scroll base circle radius with scroll height for iso-volume scrolls at various scroll inlet temperature. 
Table 2. Computer system hardware and system configuration

\begin{tabular}{|l|l|}
\hline Operating system & Windows Enterprise 64-bit \\
\hline Processor & Intel(R) Core(TM) i7-4790K CPU @ 4.00 GHz \\
\hline RAM & 8 GB \\
\hline Programming environment & MATLAB R2010a coupled to REFPROP 9.0 \\
\hline
\end{tabular}

Number of chambers required to avoid under/over expansion is presented in Fig. 8 for the geometries presented in the previous figure when all the loss mechanisms in the model are neglected or switched off. For the fixed scroll inlet temperature, the number of chambers required to achieve perfect expansion increase but at a very slow rate. Increase in number of these chambers with the scroll inlet temperature is the signature of increased volume expansion ratio in the cycle. In subsequent analysis, number of chambers in the geometries generated above is kept fixed.

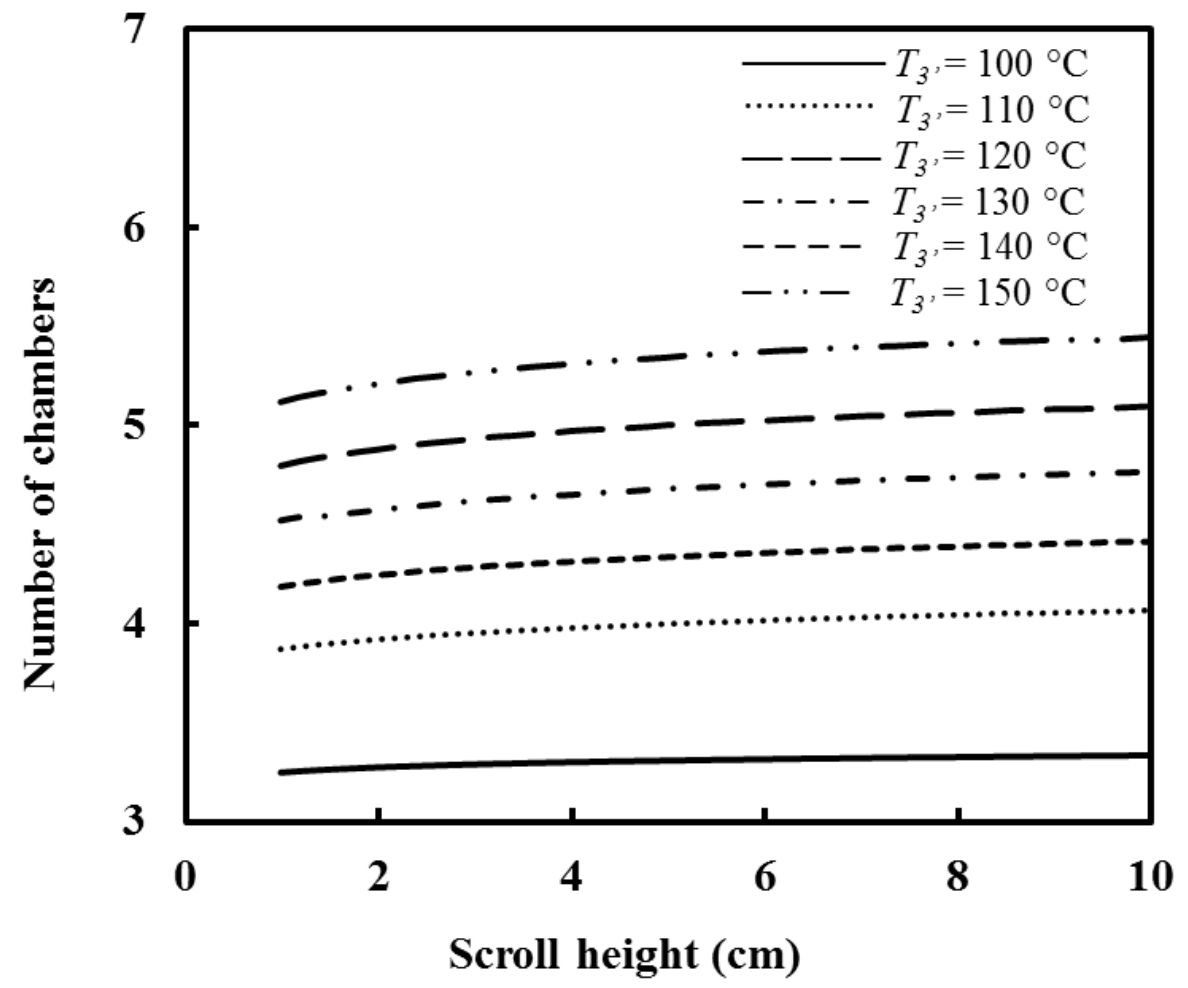

Fig. 8. Variation of number of chambers with scroll height. 
Having fixed the geometric specifications, these geometries are then evaluated against

their isentropic efficiencies to arrive at the geometry with minimum overall losses. Also to understand the relative weightage of these losses towards the overall losses, they are presented in their fractional form as defined below,

$$
\eta_{\text {loss }, X}=1-\frac{\text { scroll work in case loss ' } X \text { ' is switched on }}{\text { scroll work with all loss switched off }}
$$

$X$ in the above equation represents the loss model referred to. Methodology followed in the estimation of the efficiency loss due to a particular loss, say $X$, is to keep the loss $X$ switched on with all other losses switched off. Subsequent discussion presents the losses considered in this paper in their fractional form.

Fractional efficiency loss due to supply pressure drop (Loss $p_{\text {supply }}$ ) is plotted in Fig. 9 for the database of geometries presented in Fig. 7. For a fixed scroll inlet isotherm, this loss is observed to increase with scroll height, roughly at a constant rate. This is attributed to the decreased available inlet area for the suction process which in turn is due to the decreased base circle radius. However, an increase in scroll inlet temperature marks a decline in the supply pressure drop loss. This is again rationalized on the basis of decreasing mass flow rate due to increase in both, cycle efficiency and suction fluid density with scroll inlet temperature to generate the identical shaft power. 


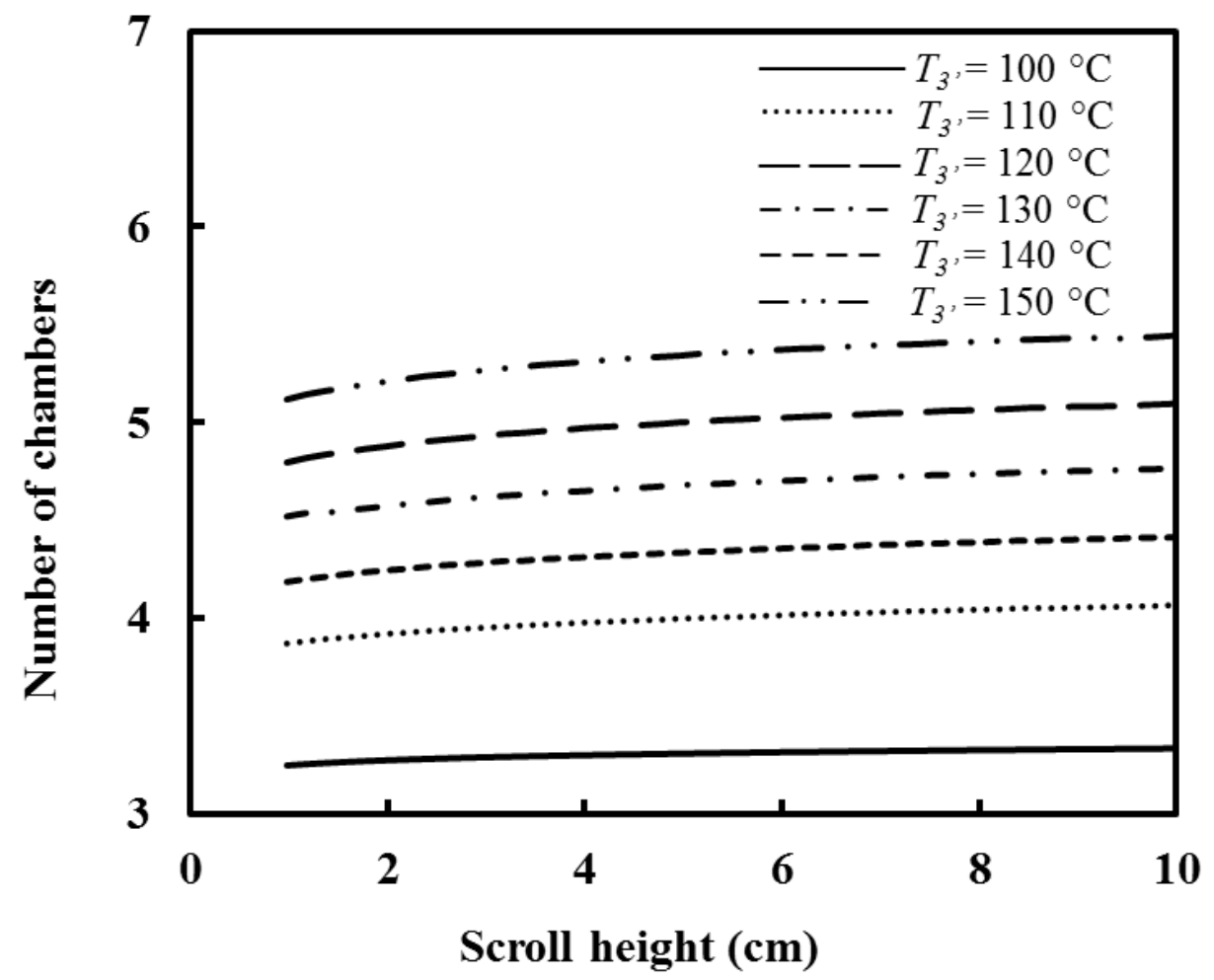

Fig. 9. Variation of Supply Pressure drop losses with scroll height.

On the similar lines, fractional efficiency loss due to flank leakage (Loss flank leakage) is presented in Fig. 10. For a given scroll inlet isotherm, geometries with greater height exhibit increased flank leakage loss. Rate of increase in this loss is found to be nearly linear. This can be asserted to the increased flank leakage area which in turn is directly proportional to the scroll height. However, when moved to a higher scroll inlet isotherm while keeping the scroll height identical, Loss flank leakage is found to decline. This is rationalized using the principles of entropy generation. In general, leakages occurring in the closed container with reduced dead mass cause less entropy generation. In case of flank leakages, though the amount of mass leaked along the flank from the first few chambers increases with the scroll inlet temperature, they leak into the chambers holding reduced gas mass. This has a net effect of the reduced entropy generation and hence, the loss associated with the flank leakages decreases with the scroll inlet temperature. 


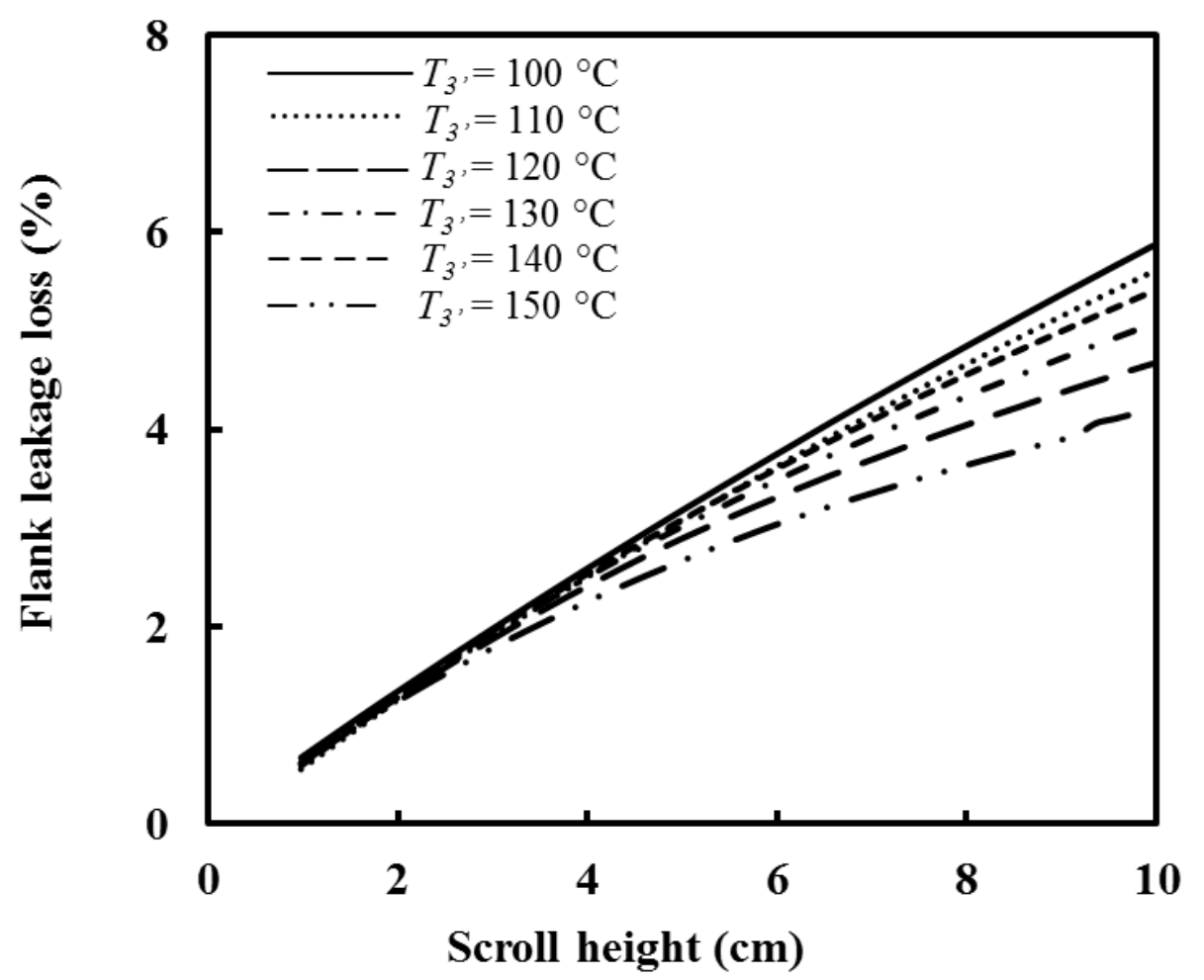

401

Fig. 10. Variation of Flank leakage loss with scroll height.

402

Loss due to radial leakage (Loss radial leakage) is plotted in Fig. 11. It is shown that for the geometries lying on the fixed scroll inlet isotherm, Loss $s_{\text {radial leakage }}$ keeps decreasing with the scroll height. This is due to the decreasing trend observed in the area associated with radial leakage which is turn is directly proportional to the involute base circle radius. Hence, there is qualitative similarity between the trend of involute base circle radius (Fig. 7) and radial leakage loss (Fig. 11). However, with increase in the scroll inlet temperature, Loss radial leakage increases for the identical scroll heights. This is contrary to the effect of temperature 410 observed on the efficiency loss due to flank leakage. Here, in case of radial leakage, increase in the amount of mass leaked is found to be a way higher than the decreased dead mass trapped in the adjacent chambers. 


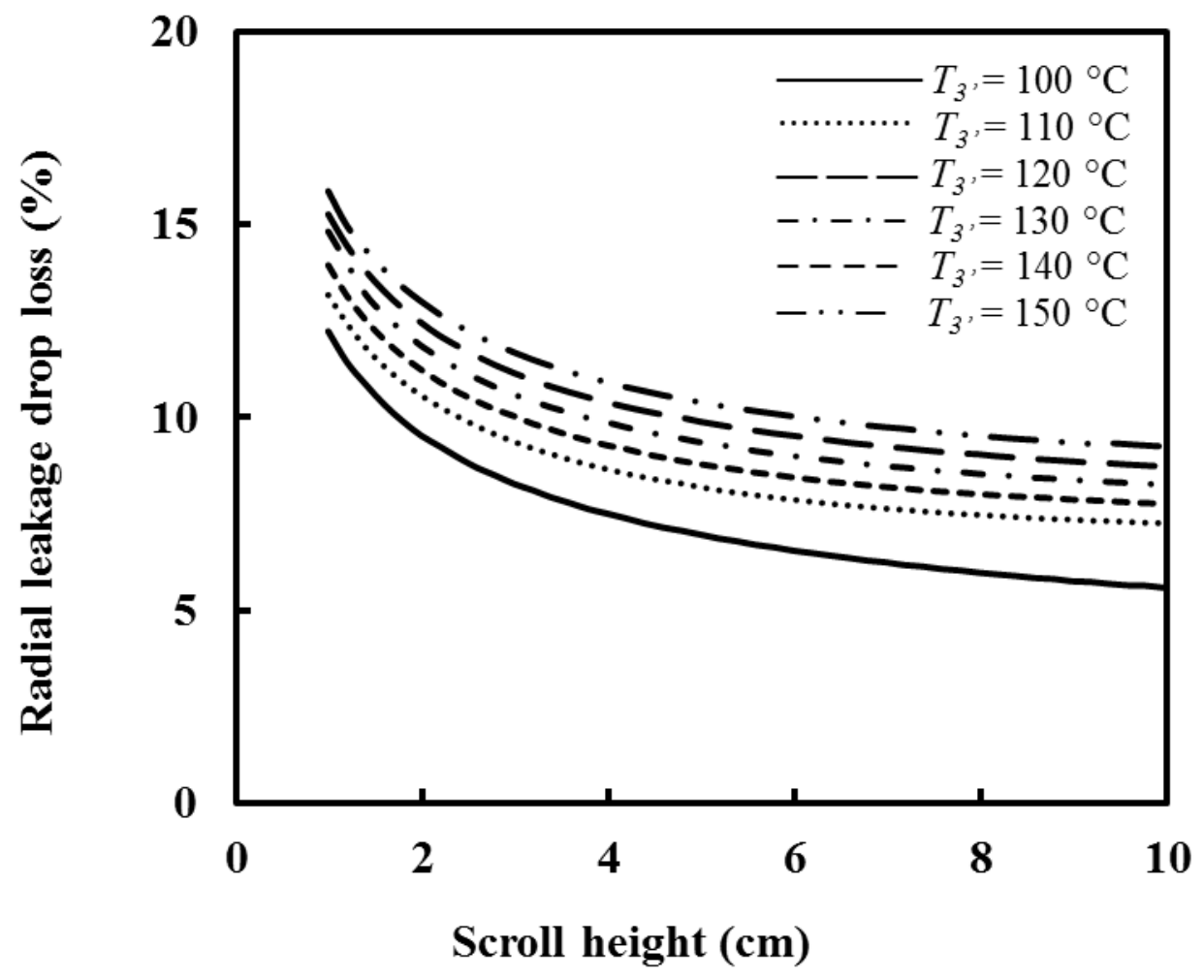

Fig. 11. Variation of Radial leakage loss with scroll height.

Losses observed at the exhaust of scroll expander occur in form of under or over expansion (Loss under/over expansion). Fig. 12 captures the loss in efficiency associated with this loss for various geometries presented earlier. In general, these losses can be avoided if the number of chambers is adequately designed. In this paper, the criterion to select the number of these chambers is based on achieving the perfect expansion in the ideal scenario (when all the losses are absent). However, in a real scenario, losses due to supply pressure drop and leakage cause a part of the gas trapped in the closed chambers to bypass to the discharge chamber which is subjected to the condenser pressure $\left(p_{4}\right)$ of 12.01 bar. Since the gas bypassing to the discharge chamber is always at a higher pressure, scroll expanders analyzed in this paper experience under expansion. For the fixed scroll inlet temperature, Loss under/over expansion exhibits a sharp minimum with respect to the scroll height unlike the earlier studied losses that either decrease or increase with height. This minimum in turn corresponds to a 
scroll height resulting in the minimum amount of under expansion (in terms of $p_{e x}-p_{4}{ }^{\prime}$ ). With increase in scroll inlet temperature, Loss under/over expansion increases which is attributed to the increased gas pressure at the inlet and the outlet of the scroll.

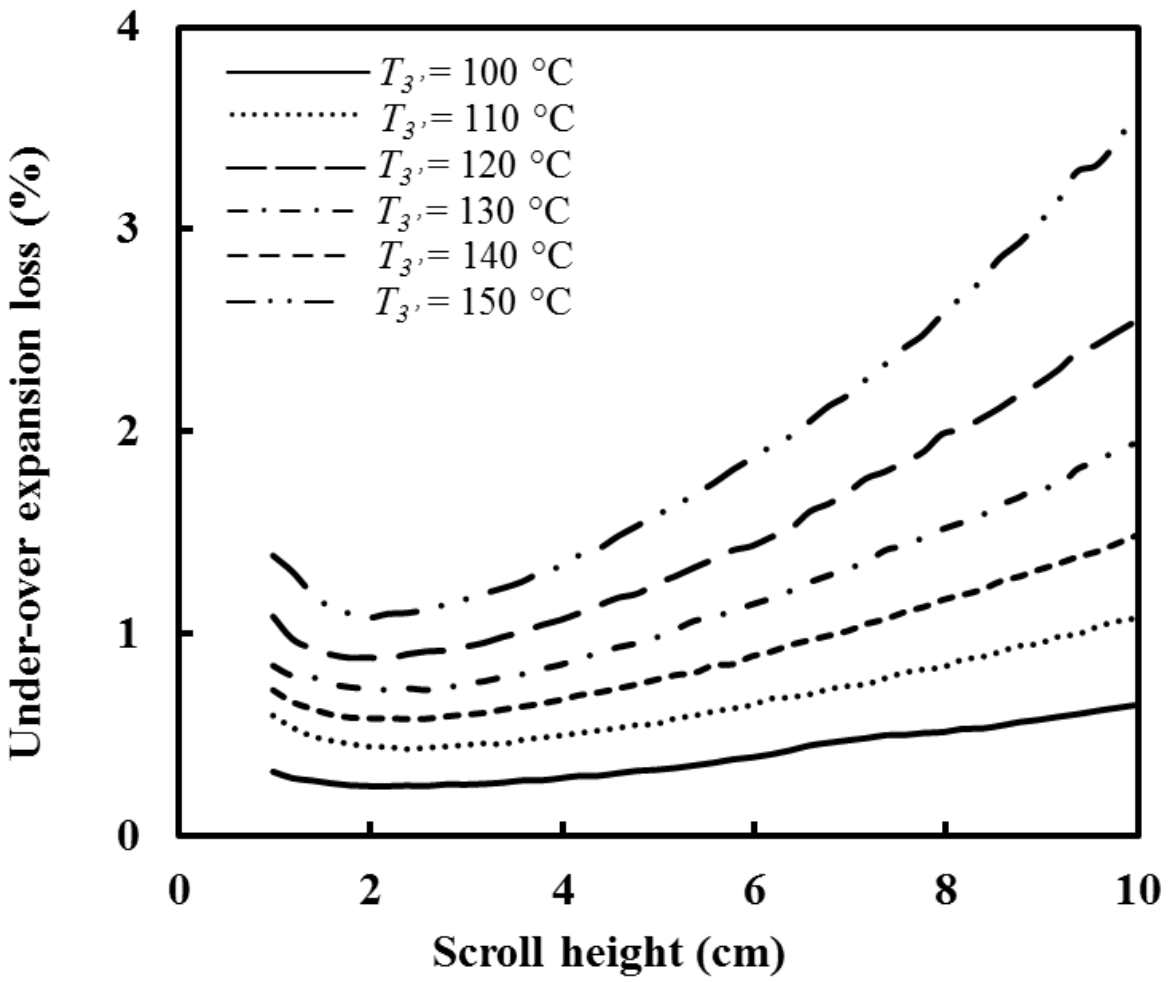

Fig. 12. Variation of under-over expansion loss with scroll height.

On similar lines, the major mechanical losses that occur in the journal and the trust bearing equivalent of the scroll are estimated in Figs. 13 and 14, respectively. Both the losses exhibit a sharp minimum as observed in the Loss under/over expansion. While the journal bearing losses are found to be a strong function of scroll inlet temperature, thrust bearing losses are almost independent of scroll inlet temperature, particularly for the scrolls with higher height. However, their strong dependence on the scroll height could not have been captured in a lumped model to estimate the mechanical losses. While the efficiency loss due to supply pressure drop is found to be the least, losses due to leakages and friction in mechanical 

the geometric feature of a scroll expander.

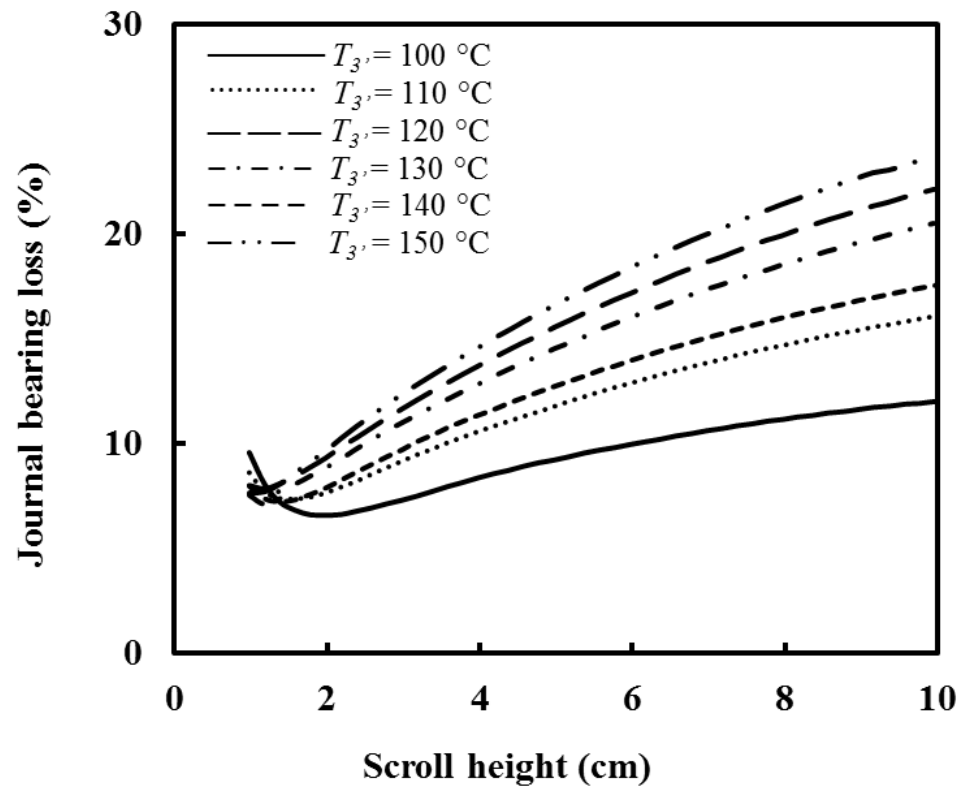

Fig. 13. Variation of Journal bearing losses and Crank pin loss with scroll height.

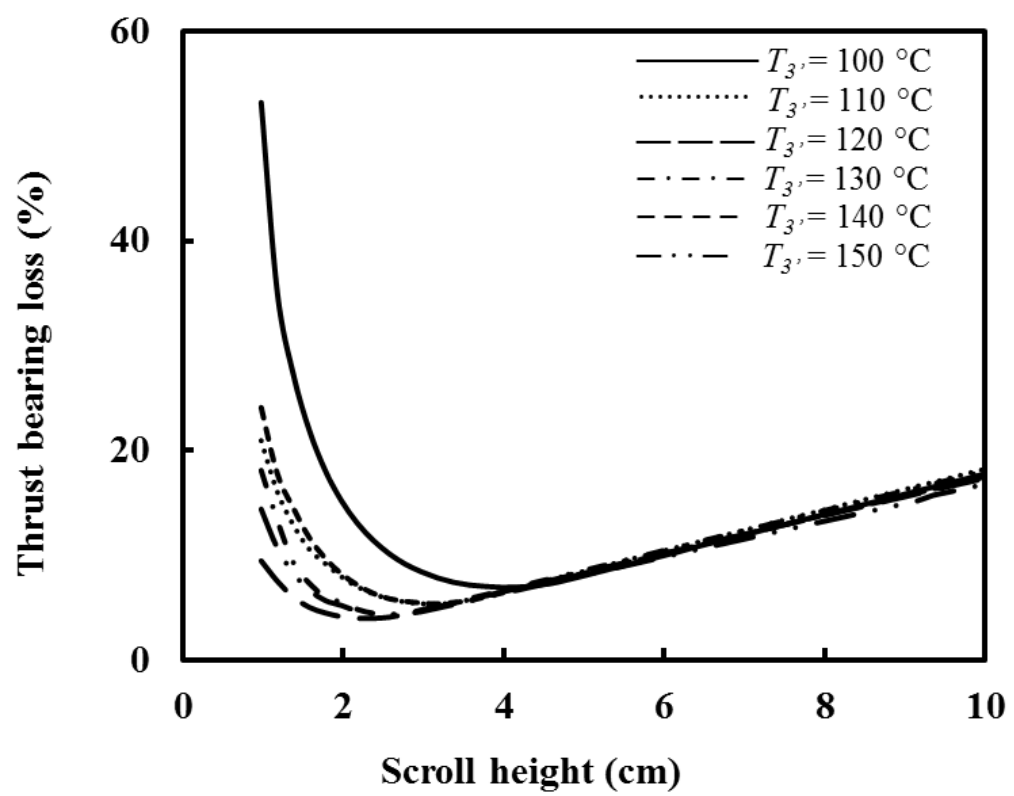

Fig. 14. Variation of Thrust bearing losses with scroll height. 
Having presented the breakup of losses, these geometries are finally evaluated against

i. For each scroll inlet isotherm, there exists a unique scroll height for which the inherent losses are minimized and isentropic efficiency is maximized.

ii. On the left side of the maxima on these isotherms, isentropic efficiency of scroll decreases drastically compared to the right side of isotherms where the rate of decrease in isentropic efficiency with scroll height is small and almost linear.

iii. Locus of maximum of these isotherms follows a notable trend as shown in Fig. 16. While the aspect ratio of the best geometries keeps increasing with the scroll inlet temperature, their isentropic efficiency keeps decreasing. This is primarily because of the rising scroll inlet pressure requirements as the scroll inlet temperature goes up. Had the scroll inlet pressure not increased with the scroll inlet temperature, the optimum aspect ratio is found to decrease as reported in our previous work. Similarly, isentropic efficiency of these geometries is found to slightly decrease with the scroll inlet pressure. This analysis is further extended to a number of working fluids. 


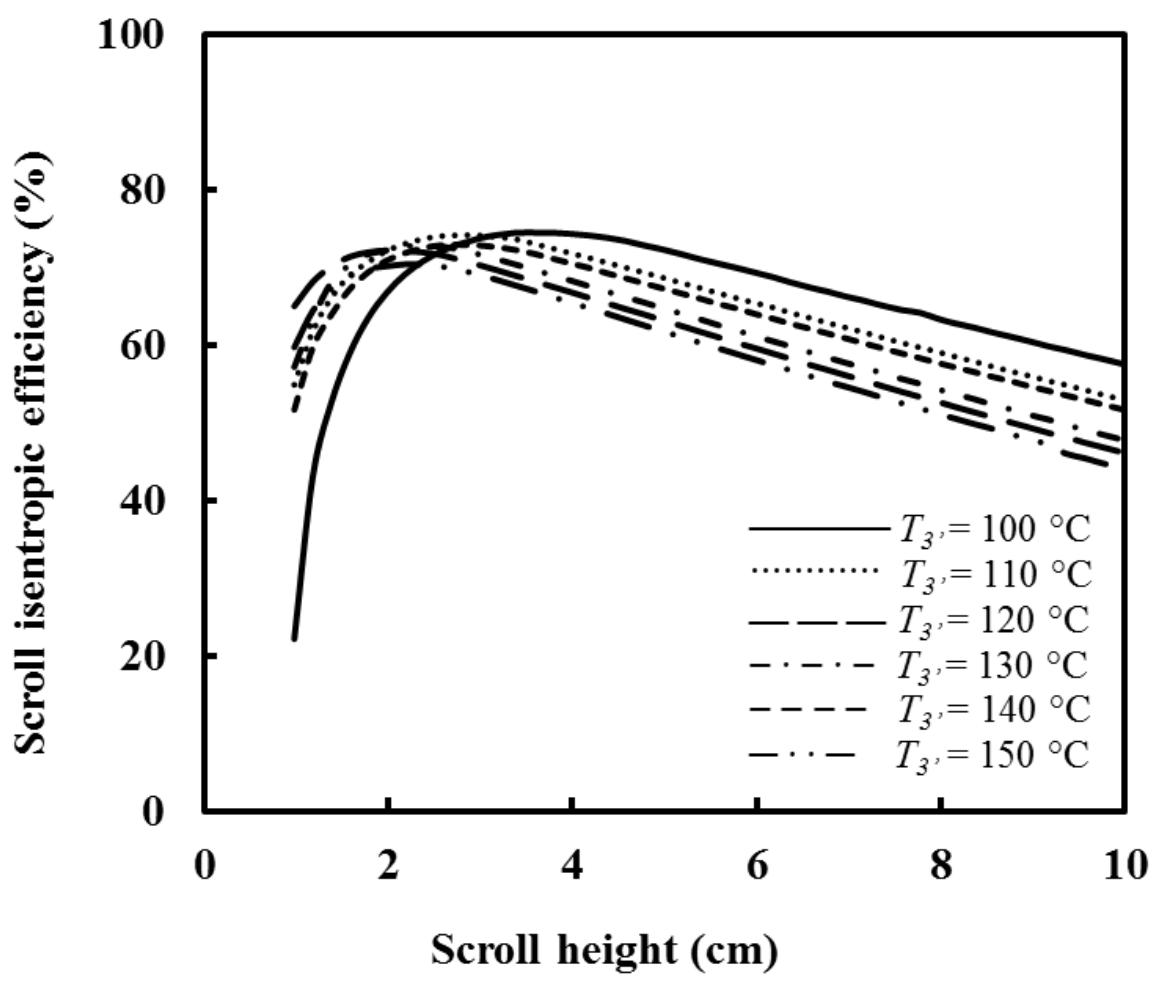

Fig. 15. Variation of overall Isentropic efficiency with scroll height.

Scroll inlet pressure (bar)

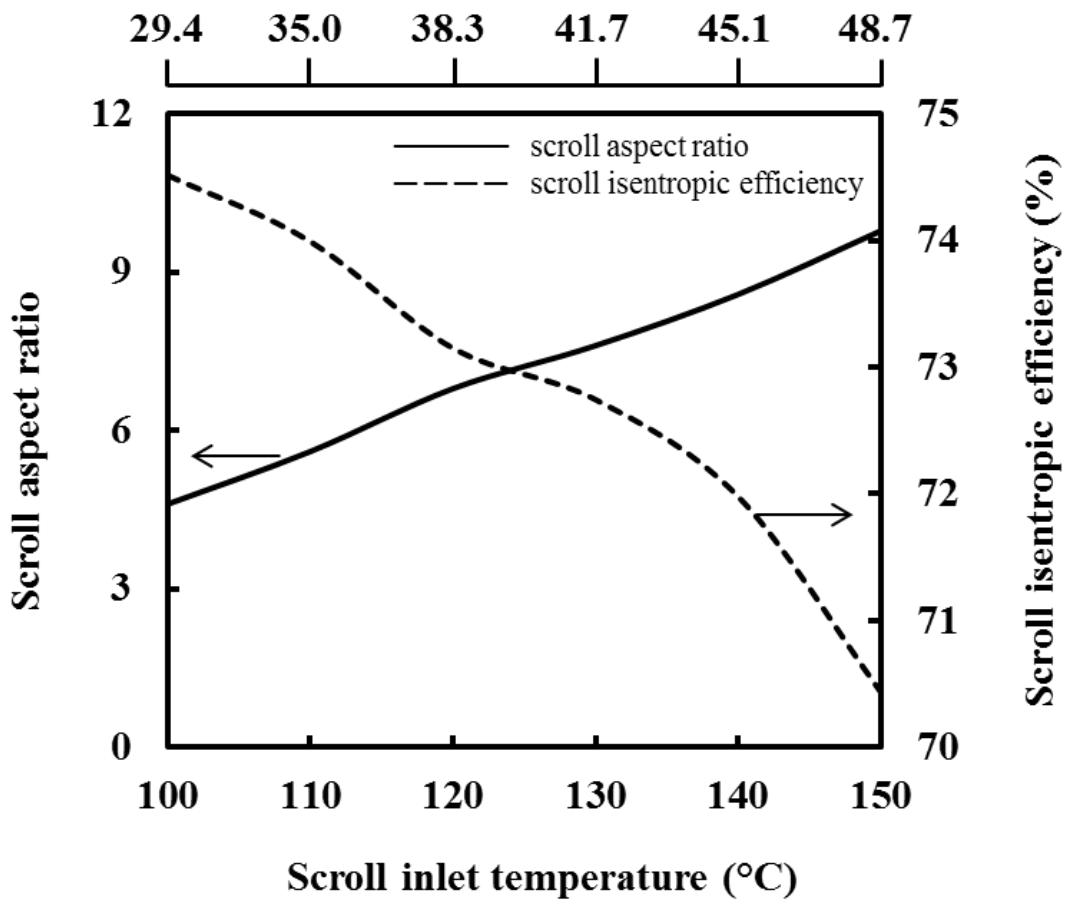

Fig. 16. Scroll aspect ratio and the scroll isentropic efficiency for various supply 


\subsection{Scroll expander design for various working fluids}

Having performed a detailed investigation of the geometric features for designing a scroll expander, the analysis is extended to the study of working fluid impact on the scroll expander design. These fluids include isopentane, R245ca, R245fa, isobutane, butane, R152a and R134a. Table 3 gives the details of their condenser pressures corresponding to $45^{\circ} \mathrm{C}$.

Fig. 17 represents the volume ratio corresponding to the optimum cycle efficiency exhibited by these fluids at various scroll inlet temperatures. It can be appreciated that the low condenser pressure fluids result in the higher volume ratio requirement and vice versa. This has a major implication on the scroll sizing and will be discussed in detail in the subsequent sections. Further, it is noted that the volume ratio in some cases (low condenser pressure fluid operating at high scroll inlet temperature) can be as high as 9. Design of scroll expander for such a volume ratio can result in the formation of large number of closed chambers in the scroll expander $(>10)$. These scroll expanders are undesirable considering manufacturing challenges and low isentropic efficiencies. Hence, whenever the volume ratio of working fluid is above 5, the expansion process in this paper is executed in the two scroll expanders used in series with the volume ratio of each defined as the square root of the volume ratio required by the thermodynamic cycle. 
Table 3. Property data for the various working fluids considered for analysis in this paper

493

494

94

\begin{tabular}{llll}
\hline Working fluids & $T_{\text {critical }}\left({ }^{\circ} \mathrm{C}\right)$ & $P_{\text {critical }}($ bar $)$ & $P_{\text {saturation }}$ (bar) at $45^{\circ} \mathrm{C}$ \\
\hline isopentane & 187.2 & 33.78 & 1.76 \\
R245ca & 174.42 & 39.25 & 2.05 \\
R245fa & 154.01 & 36.51 & 2.94 \\
butane & 151.98 & 37.76 & 4.34 \\
isobutane & 134.6 & 36.3 & 6.04 \\
R152a & 113.26 & 45.16 & 10.36 \\
R134a & 101.06 & 40.6 & 11.59 \\
\hline
\end{tabular}

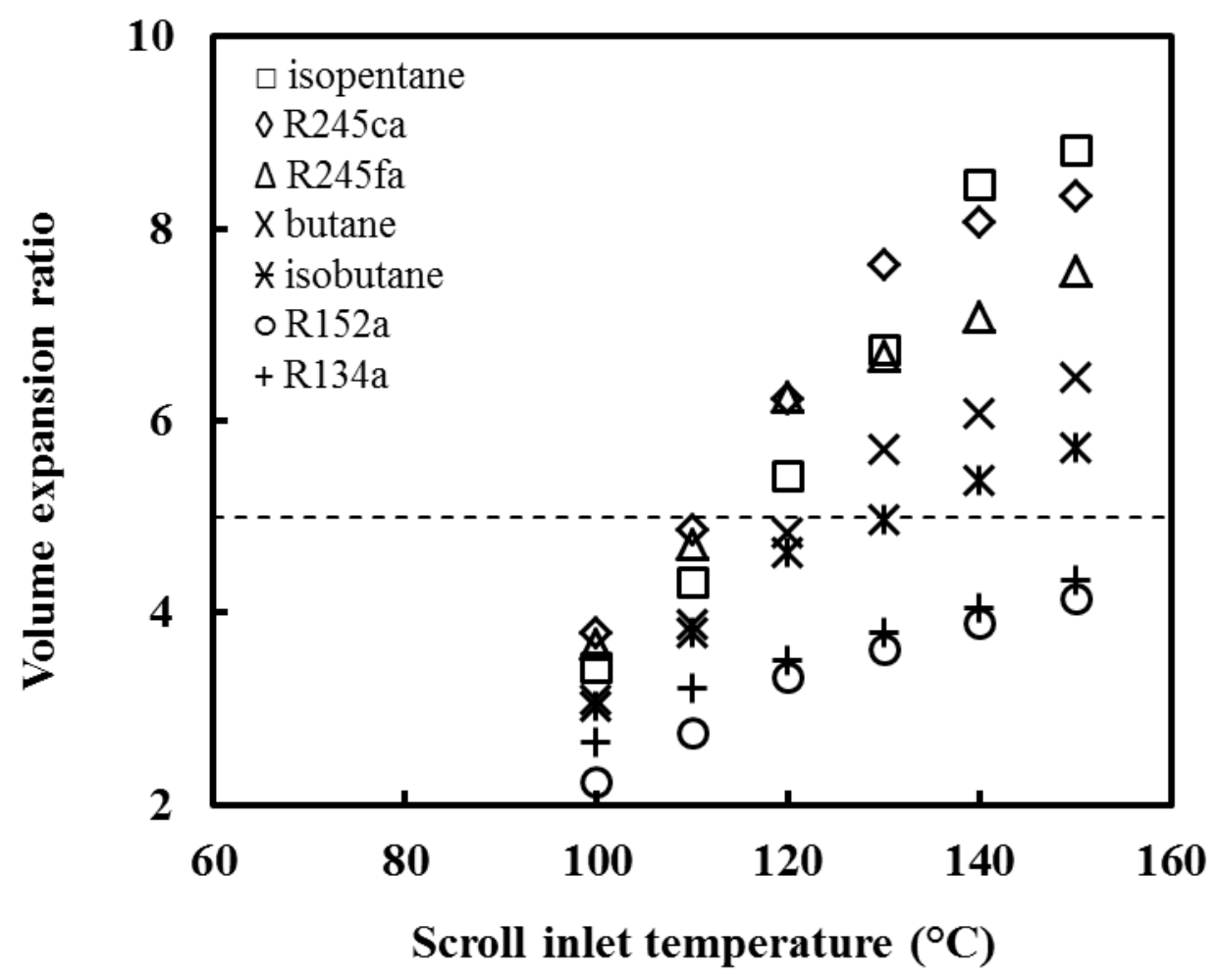

Fig. 17. Volume expansion ratio corresponding to the best cycle efficiency for various working fluids and scroll inlet temperatures.

Fig. 18 shows the variation of isentropic efficiency corresponding to the best geometries for the above mentioned working fluids and scroll inlet temperatures. For a given fluid, scroll efficiency in most of the cases decreases with increase in the scroll inlet 
temperature unless it uses two scroll expanders in series. While making the transition from a single scroll to two scrolls, scroll efficiency either decreases or increases. For low condenser pressure fluids like isopentane and R245ca, efficiency upon transition increases, whereas the opposite is observed for the high condenser pressure fluids such as butane and isobutane. Very high condenser pressure fluids such as R134a and R152a use only one scroll expander in the interest of temperatures. In general, it can be appreciated that it is possible to design the scroll expanders for any given working fluid and its operating conditions in a range of 68 to $78 \%$ scroll isentropic efficiency.

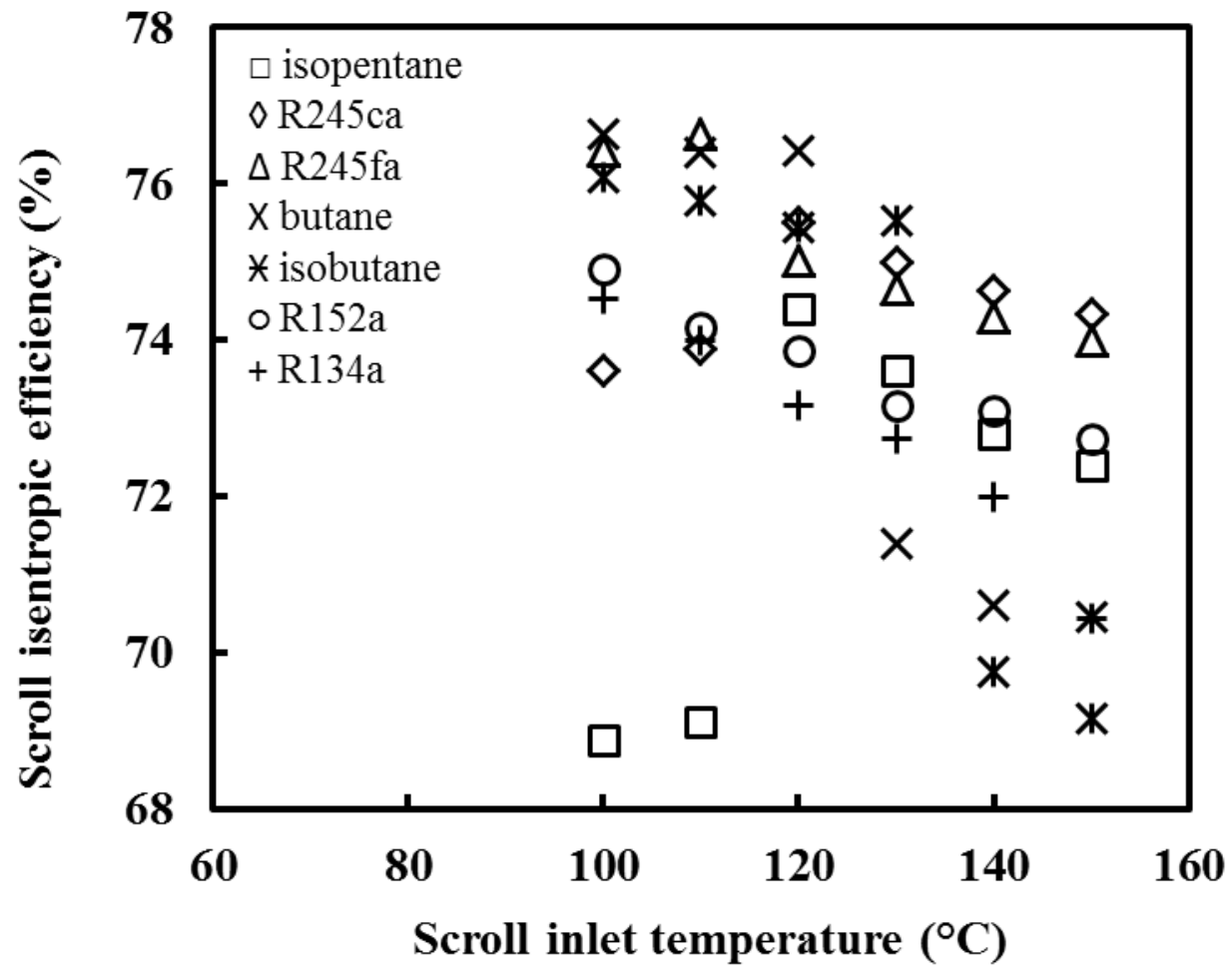

Fig. 18. Scroll isentropic efficiency corresponding to the best cycle efficiency for various working fluids and scroll inlet temperatures.

Effect of working fluid and its operating conditions on the scroll expander size is captured by plotting the power density which is defined as the ratio of scroll work to the scroll volume (Fig. 19). Here, the scroll volume is referred to the cylindrical volume occupied 

by the fixed scroll. For any given working fluid, it is observed that the power density marginally decreases with the scroll inlet temperature. However, when the transition is made

519 from the use of one to two scrolls, power density observes an upward jump. Further, power 520 density is found to be directly linked to the condenser pressure of the working fluid. 521 Increasing the condenser pressure increases the power density which is the result of compact scroll expander realized for the identical operating conditions. This, in theory, could result in cost savings for high pressure fluid scroll expanders if designed to withstand higher 524 pressures.

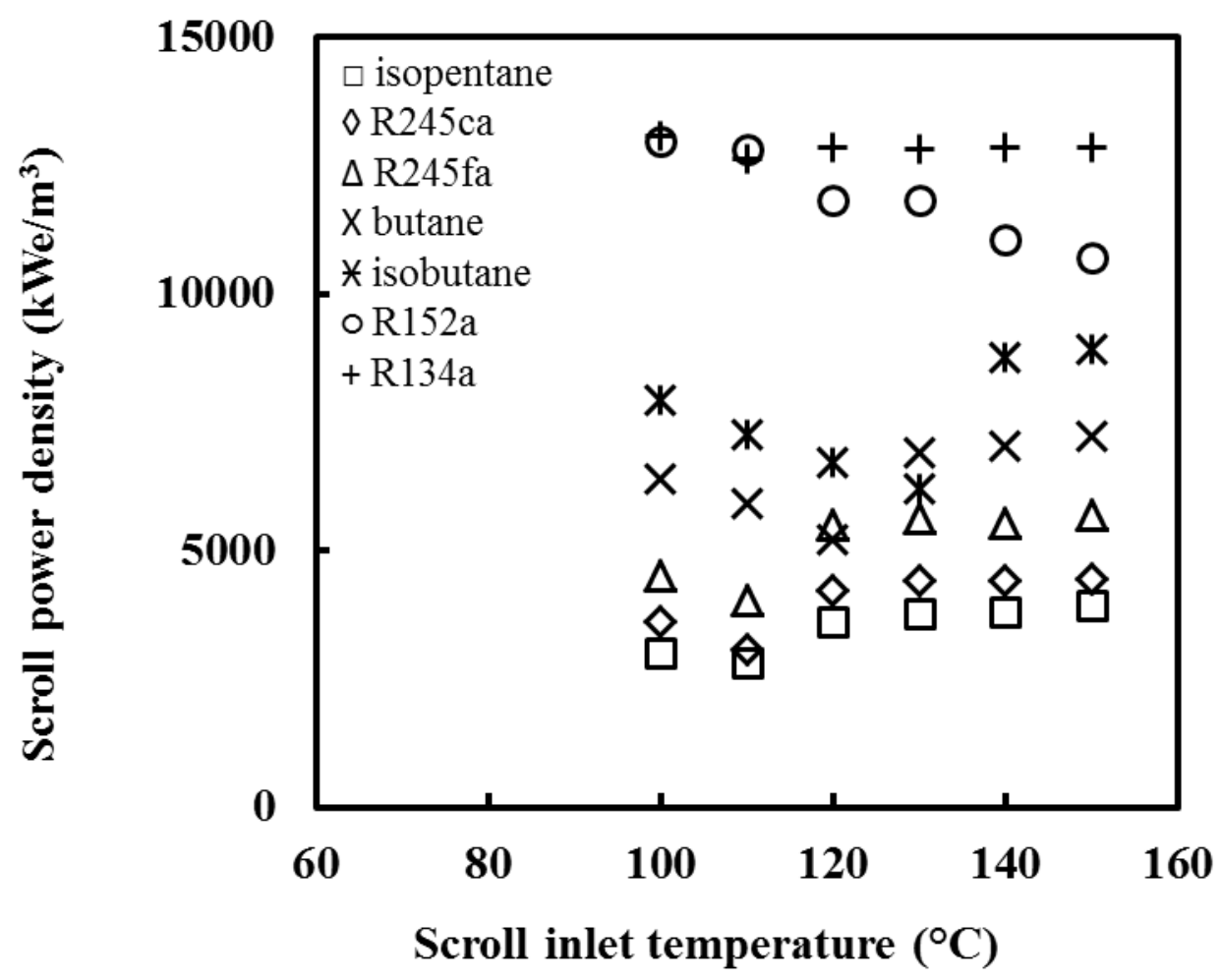

Fig. 19. Scroll power density corresponding to the best cycle efficiency for various working fluids and scroll inlet temperatures. 


\section{Conclusions}

Design of a scroll expander specific to an ORC application often involves a number of variables including geometric features, working fluid and operating conditions in the power cycle. This paper provides a detailed step-by-step design strategy and guidelines to design scrolls expanders for the specific ORC requirements. Algorithm presented in this work involves the estimation of various losses due to leakage, supply pressure drop, under/over expansion and mechanical losses for various scroll geometries for a given set of thermodynamic operating conditions. The model developed in the paper is validated and a detailed analysis is carried out for R134a as a working fluid followed by a number of working fluids. Key conclusions drawn from the paper are as follows:

i. Design of scroll expander is highly sensitive to the cycle operating conditions which must be optimized for the best cycle efficiency to realize the best performance.

ii. For the specified operating conditions and power capacity in the ORC, a number of scroll geometries are feasible by varying the scroll height and the involute base circle radius. These geometries need to be evaluated against various losses inherent to them to find the one with minimum losses.

iii. The losses are a strong function of the geometric features with the minimization of each favoring different domains of the scroll height. While flank leakage losses favor lower scroll heights, radial leakage losses prefer higher heights. Similarly, a minimum in the mechanical losses exhibits a sharp optimum scroll height.

iv. In order to minimize the losses associated with under/over expansion, built-in volume ratio should match the working fluid volume ratio across the expansion process. This can result in large number of chambers in case of low condenser pressure fluids that need high volume ratios in the scroll. Examples of these fluids are isopentane, R245ca and R245fa. 
554 Thus, these fluids need two or more scroll expanders in series to meet the cycle volume ratio requirements.

v. High condenser pressure fluids demand less number of chambers and offer high power densities which could theoretically lead to cost savings. This makes the scroll expander more suited for the relatively high pressure fluids such as R152a and R134a ( 50 bar).

Future work involves the presentation of scroll expanders on the classical $N_{s}-D_{s}$ diagram to facilitate the rapid selection of efficient scroll expander geometries for the specific project requirements.

\section{References}

[1] H.M. Curran, Use of organic working fluids in Rankine engines, (1979). doi:DOE/CS/30202-T1.

[2] T.C. Hung, T.Y. Shai, S.K. Wang, A review of organic rankine cycles (ORCs) for the recovery of low-grade waste heat, Energy. 22 (1997) 661-667. doi:10.1016/S03605442(96)00165-X.

[3] H. Chen, D.Y. Goswami, E.K. Stefanakos, A review of thermodynamic cycles and working fluids for the conversion of low-grade heat, Renew. Sustain. Energy Rev. 14 (2010) 3059-3067. doi:10.1016/j.rser.2010.07.006.

[4] B.F. Tchanche, G. Lambrinos, A. Frangoudakis, G. Papadakis, Low-grade heat conversion into power using organic Rankine cycles - A review of various applications, Renew. Sustain. Energy Rev. 15 (2011) 3963-3979. doi:10.1016/j.rser.2011.07.024.

[5] D. Fiaschi, G. Manfrida, F. Maraschiello, Thermo-fluid dynamics preliminary design of turbo-expanders for ORC cycles, Appl. Energy. 97 (2012) 601-608. doi:10.1016/j.apenergy.2012.02.033. 
[6] R.B. Peterson, H. Wang, T. Herron, Performance of a small-scale regenerative Rankine power cycle employing a scroll expander, Proc. Inst. Mech. Eng. Part A J. Power Energy. 222 (2008) 271-282. doi:10.1243/09576509JPE546.

[7] R. Zanelli, D. Favrat, Experimental investigation of a hermetic scroll expandergenerator, 12th Int. Compress. Eng. Conf. Purdue. (1994) 459-464. http://docs.lib.purdue.edu/cgi/viewcontent.cgi?article=2020\&context=icec.

[8] G. Qiu, H. Liu, S. Riffat, Expanders for micro-CHP systems with organic Rankine cycle, Appl. Therm. Eng. 31 (2011) 3301-3307. doi:10.1016/j.applthermaleng.2011.06.008

[9] G. Ricci, G. Viviani, Maintenance operations in geothermal power plants, Geothermics. 2 (1970) 839-847. doi:http://dx.doi.org/10.1016/0375-6505(70)90085-4.

[10] T. Yanagisawa, M.D. Cheng, M. Fukuta, T. Shimizu, Optimum Operating Pressure Ratio for Scroll Compressor, in: Int. Compress. Eng. Conf., 1990: pp. 425-433. doi:http://docs.lib.purdue.edu/icec/732.

[11] Y.R. Lee, W.F. Wu, On the profile design of a scroll compressor, Int. J. Refrig. 18 (1995) 308-317. doi:10.1016/0140-7007(95)00013-2.

[12] E. Winandy, C.S. Saavedra O, J. Lebrun, Experimental analysis and simplified modelling of a hermetic scroll refrigeration compressor, Appl. Therm. Eng. 22 (2002) 107-120. doi:10.1016/S1359-4311(01)00083-7.

[13] C. Cuevas, N. Fonseca, V. Lemort, Automotive electric scroll compressor: Testing and modeling, in: Int. J. Refrig., 2012: pp. 841-849. doi:10.1016/j.ijrefrig.2011.11.019.

[14] H.J. Kim, J.M. Ahn, I. Park, P.C. Rha, Scroll expander for power generation from a low-grade steam source, Proc. Inst. Mech. Eng. Part A J. Power Energy. 221 (2007) 705-711. doi:10.1243/09576509JPE392.

[15] T.S. Saitoh, N. Yamada, S. Wakashima, Study of Solar Organic Rankine Cycle System 
using scroll expander, Nihon Kikai Gakkai Ronbunshu, B Hen/Transactions Japan Soc. Mech. Eng. Part B. 71 (2005) 986-992.

http://www.scopus.com/inward/record.url?eid=2-s2.019944410214\&partnerID=tZOtx3y1.

[16] H. Wang, R.B. Peterson, T. Herron, Experimental performance of a compliant scroll expander for an organic Rankine cycle, Proc. Inst. Mech. Eng. Part A J. Power Energy. 223 (2009) 863-872. doi:10.1243/09576509JPE741.

[17] J.A. Mathias, J.R. Johnston, J. Cao, D.K. Priedeman, R.N. Christensen, Experimental Testing of Gerotor and Scroll Expanders Used in, and Energetic and Exergetic Modeling of, an Organic Rankine Cycle, J. Energy Resour. Technol. 131 (2009) 012201. doi:10.1115/1.3066345.

[18] V. Lemort, S. Quoilin, C. Cuevas, J. Lebrun, Testing and modeling a scroll expander integrated into an Organic Rankine Cycle, Appl. Therm. Eng. 29 (2009) 3094-3102. doi:10.1016/j.applthermaleng.2009.04.013.

[19] S. Quoilin, V. Lemort, J. Lebrun, Experimental study and modeling of an Organic Rankine Cycle using scroll expander, Appl. Energy. 87 (2010) 1260-1268. doi:10.1016/j.apenergy.2009.06.026.

[20] S. Declaye, S. Quoilin, L. Guillaume, V. Lemort, Experimental study on an open-drive scroll expander integrated into an ORC (Organic Rankine Cycle) system with R245fa as working fluid, Energy. 55 (2013) 173-183. doi:10.1016/j.energy.2013.04.003.

[21] M.S. Orosz, Thermosolar and photovoltaic hybridization for small scale distributed generation: application for powpower rural health, (2012) 223.

[22] M.S. Orosz, A. V. Mueller, B.J. Dechesne, H.F. Hemond, Geometric Design of Scroll Expanders Optimized for Small Organic Rankine Cycles, J. Eng. Gas Turbines Power. 135 (2013) 042303. doi:10.1115/1.4023112. 
[23] M.S. Orosz, S. Quoilin, H. Hemond, Sorce : a Design Tool for Solar Organic Rankine Cycle Systems in Distributed Generation Applications, (n.d.).

[24] R. Dickes, Design and fabrication of a variable wall thickness two-stage scroll expander to be integrated in a micro-solar power plant, Department of Aerospace and Mechanical engineering, University of Liège, 2013.

[25] H.J. Kim, J.M. Ahn, S.O. Cho, K.R. Cho, Numerical simulation on scroll expandercompressor unit for CO2 trans-critical cycles, Appl. Therm. Eng. 28 (2008) 16541661. doi:10.1016/j.applthermaleng.2007.11.002.

[26] P. Song, M. Wei, L. Shi, S.N. Danish, C. Ma, A review of scroll expanders for organic Rankine cycle systems, Appl. Therm. Eng. 75 (2015) 54-64. doi:10.1016/j.applthermaleng.2014.05.094.

[27] L. Guangbin, Z. Yuanyang, L. Liansheng, S. Pengcheng, Simulation and experiment research on wide ranging working process of scroll expander driven by compressed air, Appl. Therm. Eng. 30 (2010) 2073-2079. doi:10.1016/j.applthermaleng.2010.05.015.

[28] E. Morishita, M. Sugihara, T. Inaba, T. Nakamura, Scroll Compressor Analytical Model, Engineering. (1984).

[29] N. Ishii, M. Fuhushima, K. Sano, K. Sawai, A study on dynamic behavior of scroll compressor, in: Int. Compress. Eng. Conf., 1986: p. Paper 578.

[30] N. Ishii, S. Yamamoto, S. Muramtsu, M. Yamamura, M. Takahashi, Optimum Combination of Parameters for High Mechanical Efficiency of a Scroll Compressor, Int. Compress. Eng. Conf. (1992) 8. http://docs.lib.purdue.edu/icec/798.

[31] S. Etemad, J. Nieter, Computational Parametric Study of Scroll Compressor Efficiency , Design , and Manufacturing Issues, Int. Compress. Eng. Conf. (1988).

[32] P. Garg, P. Kumar, K. Srinivasan, P. Dutta, Evaluation of isopentane, R-245fa and 
their mixtures as working fluids for organic Rankine cycles, Appl. Therm. Eng. 51 (2012) 292-300. doi:10.1016/j.applthermaleng.2012.08.056.

[33] P. Garg, P. Kumar, K. Srinivasan, P. Dutta, Evaluation of carbon dioxide blends with isopentane and propane as working fluids for organic Rankine cycles, Appl. Therm. Eng. 52 (2012) 439-448. doi:10.1016/j.applthermaleng.2012.11.032.

[34] P. Garg, P. Kumar, K. Srinivasan, A trade-off between maxima in efficiency and specific work output of super- and trans-critical CO2 Brayton cycles, J. Supercrit. Fluids. 98 (2015) 119-126. doi:10.1016/j.supflu.2014.12.023.

[35] A. Sengupta, P. Kumar, P. Garg, N. Hui, M.S. Orosz, P. Kumar, Moment analysis of a scroll expander used in an organic Rankine cycle, in: ASME Turbo Expo 2014 Turbine Tech. Conf. Expo., 2014: p. Paper number-GT2014-26935. doi:10.1115/GT201426935.

\section{Acknowledgement}

This research is based upon work supported by the Solar Energy Research Institute for India and the U.S. (SERIIUS) funded jointly by the U.S. Department of Energy subcontract DE AC36-08G028308 (Office of Science, Office of Basic Energy Sciences, and Energy Efficiency and Renewable Energy, Solar Energy Technology Program, with support from the Office of International Affairs) and the Government of India subcontract IUSSTF/JCERDC-SERIIUS/2012 dated 22nd Nov. 2012. 
679

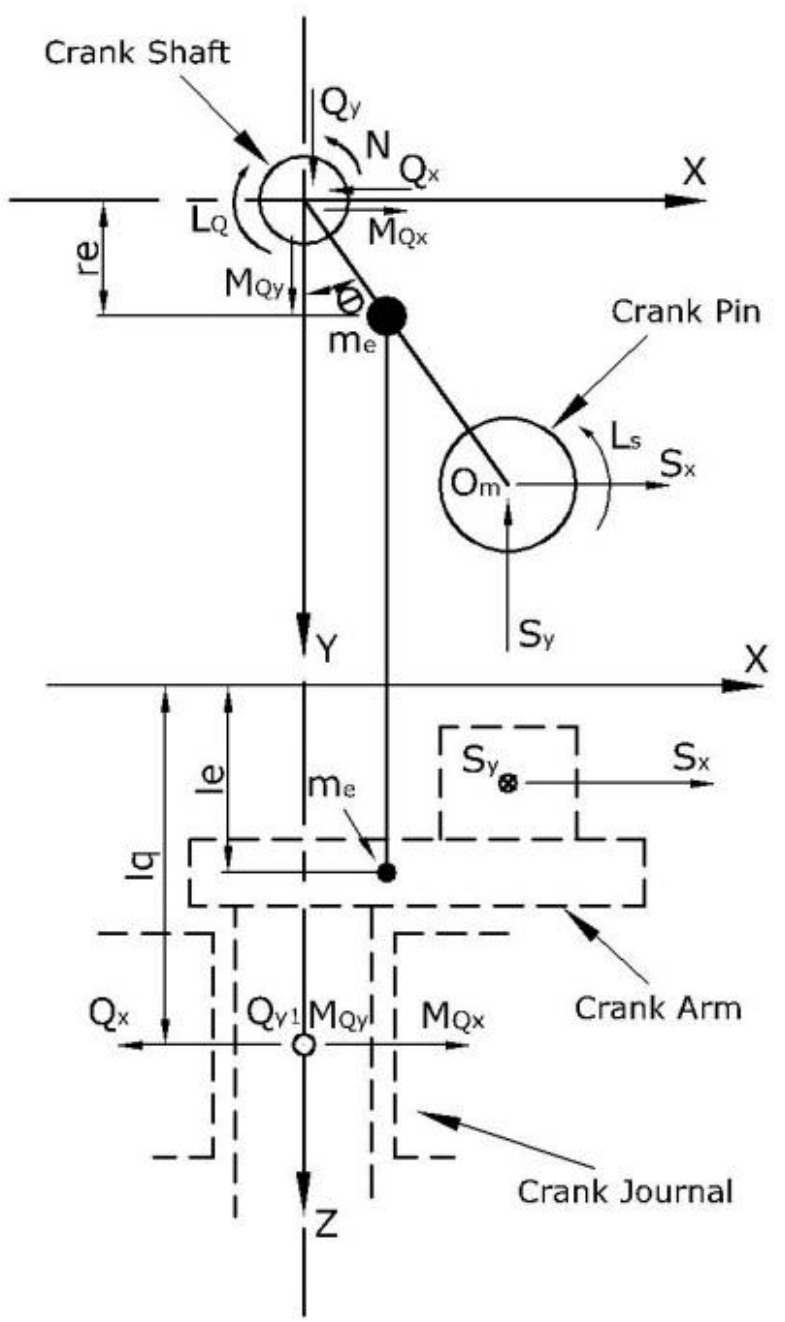




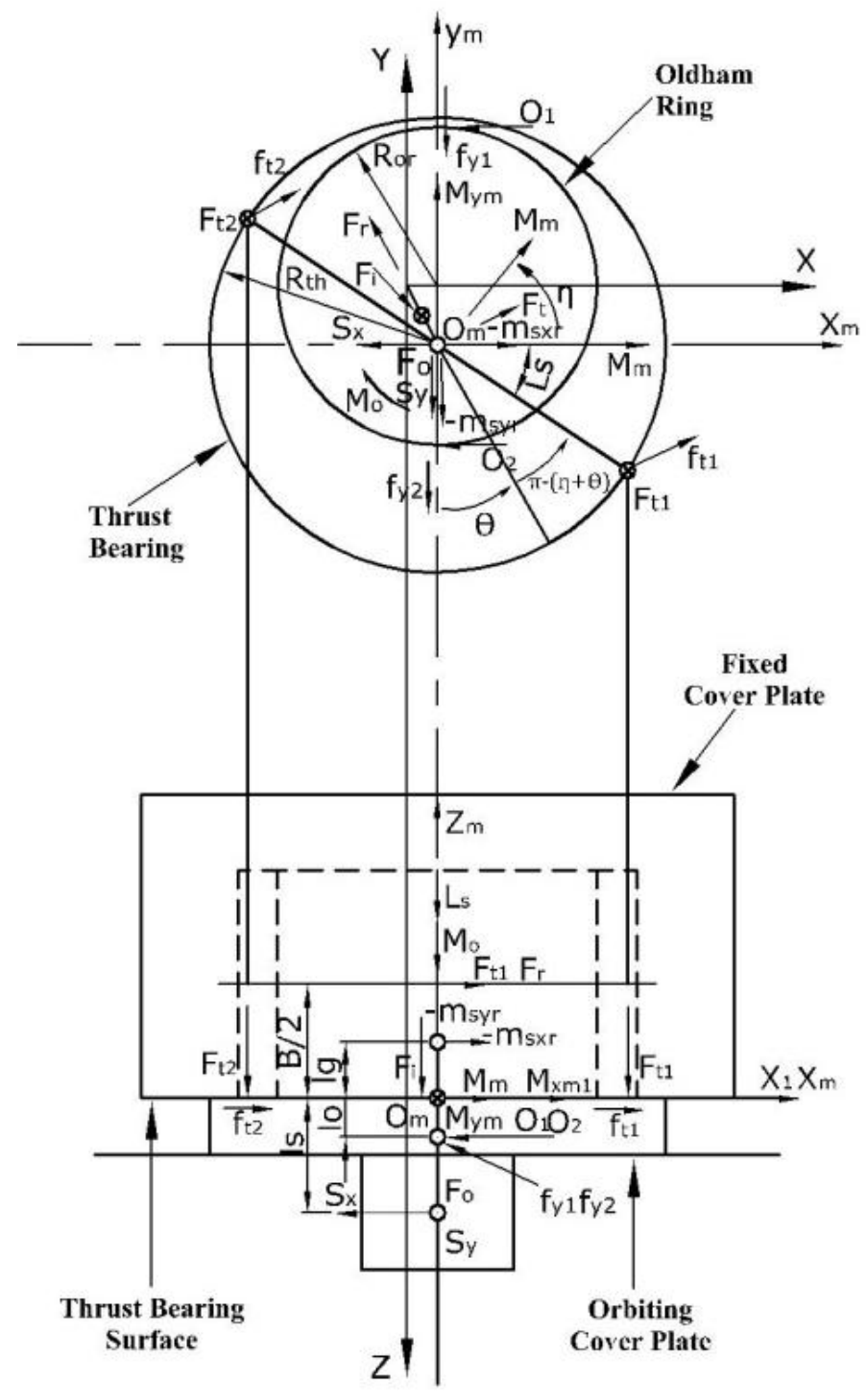

683

Fig. A2. Resolution of various forces and moments in the scroll expander 


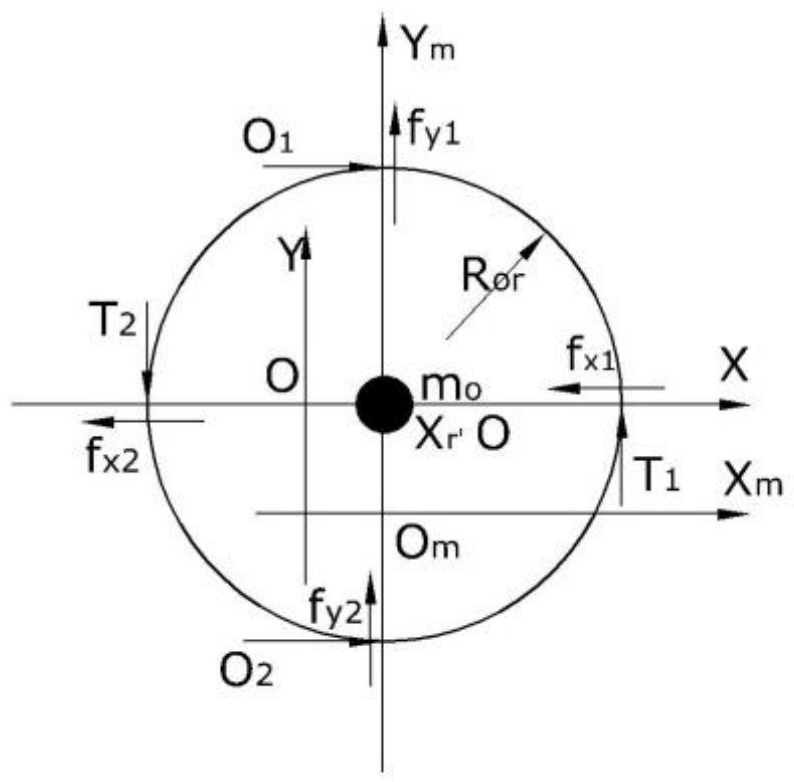

687

Fig. A3. Force and torque resolution in Oldham ring 